\title{
SUBSIDIZING FUEL EFFICIENT CARS: EVIDENCE FROM CHINA'S AUTOMOBILE INDUSTRY
}

\author{
Chia-Wen Chen \\ Wei-Min $\mathrm{Hu}$ \\ Christopher R. Knittel \\ Working Paper 23045 \\ http://www.nber.org/papers/w23045 \\ NATIONAL BUREAU OF ECONOMIC RESEARCH \\ 1050 Massachusetts Avenue \\ Cambridge, MA 02138 \\ January 2017
}

Chen gratefully acknowledges the financial support from the Ministry of Science and Technology, Taiwan (104-2410-H-305-010). We are grateful to seminar participants at the European Association for Research in Industrial Economics Annual Conference, National Taiwan University, Soochow University, Taiwan Econometric Society Annual Conference, National Chung Cheng University, Academic Sinica, Western Economic Association International Annual Conference, and NBER-CCER Annual Conference for their useful comments. The views expressed herein are those of the authors and do not necessarily reflect the views of the National Bureau of Economic Research.

NBER working papers are circulated for discussion and comment purposes. They have not been peer-reviewed or been subject to the review by the NBER Board of Directors that accompanies official NBER publications.

(C) 2017 by Chia-Wen Chen, Wei-Min Hu, and Christopher R. Knittel. All rights reserved. Short sections of text, not to exceed two paragraphs, may be quoted without explicit permission provided that full credit, including $(\odot$ notice, is given to the source. 
Subsidizing Fuel Efficient Cars: Evidence from China's Automobile Industry

Chia-Wen Chen, Wei-Min Hu, and Christopher R. Knittel

NBER Working Paper No. 23045

January 2017

JEL No. L5,L91,Q4,Q5

\begin{abstract}
$\underline{\text { ABSTRACT }}$
The Chinese automobile market is the largest in the world with annual sales exceeding 20 million vehicles. The tremendous growth in sales---over 200 percent from 2008 to 2015---and concerns over local air quality have prompted China's policy makers to incentivize the adoption of more fuel efficient vehicles. We examine the response of vehicle purchase behavior to China's largest national subsidy program for fuel efficient vehicles during 2010 and 2011. Using variation from the program's eligibility cutoffs, we find that the program boosted sales for subsidized vehicle models, but that the program also created a substitution effect within highly fuel efficient vehicles and most subsidies went to inframarginal consumers. This substitution effect greatly reduces the cost effectiveness of the program. We calculate that the average cost per ton of carbon dioxide saved is over 82 USD, well above the social cost of carbon used in U.S. regulatory filings. Using the framework in Boomhower and Davis (2014) and accounting for local pollution benefits, we show that ignoring the substitution effect would lead one to conclude that the program is welfare enhancing, whereas in fact the marginal cost of the program exceeds the marginal benefit by almost as much as 300 percent. We also show that the program was not well-targeted; the effect of the subsidy on sales of fuel efficient vehicles was smaller in areas where consumers were more likely to purchase fuel inefficient models or were lower educated.

Chia-Wen Chen

Department of Economics

National Taipei University

151, University Rd.

San Shia District

New Taipei City

23741 Taiwan

chenzoo@gmail.com

Wei-Min $\mathrm{Hu}$

Department of Public Finance

National Chenchi University

No. 64, Chih-Nan Road

Section 2, Wenshan district

Taipei, 11623

Taiwan

weiminhu@nccu.edu.tw

Christopher R. Knittel

MIT Sloan School of Management

100 Main Street, E62-513

Cambridge, MA 02142

and NBER

knittel@mit.edu
\end{abstract}




\section{Introduction}

Gasoline consumption is a major source of air pollution and carbon dioxide emissions. Various policy tools have been proposed and implemented to reduce gasoline consumption in the United States (Knittel, 2012), and similar efforts have been made in China as well. For example, China's central government launched an energy efficient program in mid-2010, subsidizing consumers who purchase new fuel efficient vehicles with an engine size less than or equal to 1.6 liters. The cash subsidy program was very popular - so much so, that it cost 12 billion RMB (1.8 billion USD) by the end of $2011 .^{1}$

Subsidizing energy efficient products (i.e., energy efficient programs) may alleviate market failures due to externalities, asymmetric information, credit constraints, and behavior biases (Allcott and Greenstone, 2012; Gillingham et al., 2009). However, government-provided subsidies may create deadweight loss in the process and place a huge financial burden on the government itself. Evaluating the degree to which energy efficient programs affect consumption decisions is thus important in designing an effective energy and environmental policy. In this line, several recent studies question the effectiveness of energy efficient programs. Boomhower and Davis (2014) adopt a regression discontinuity design to study a large-scale energy efficient program in Mexico and find that a large portion of program participants is free riders. Allcott et al. (2015) show that participants in several U.S. energy efficient programs are more likely to be wealthy environmentalists who are less subject to asymmetric information, credit constraints, or behavior biases. ${ }^{2}$

In this paper we employ detailed panel data that include vehicle sales at the model-monthprovince level to study the effectiveness of the fuel efficient subsidy program in China. Our focus is on how the program affects vehicle purchase behavior. Exploiting exogenous variation from the cutoff and the roll out of the subsidy program, we estimate the share of subsidies

\footnotetext{
${ }^{1}$ The average exchange rate between 2010 and 2011 is 1 USD $=6.6$ RMB.

${ }^{2}$ Borenstein and Davis (2015) also find that energy efficient tax credits in the U.S. are mostly received by higher-income consumers.
} 
taken up by marginal consumers and the substitution effect across vehicle types. Such estimates have important policy implications, because if most of the subsidies were taken up by inframarginal consumers or marginal consumers whose original choices were other fuel efficient vehicles, then the program is likely to be an expensive way to reduce gasoline consumption and carbon dioxide emissions. We also explore the interactions between the effect of the program and the tendency to purchase relatively fuel inefficient vehicles in order to learn more about the program's effect on targeting consumers.

Our empirical approach is based on a 'difference-in-differences' set-up. We use both the eligibility cutoffs and the effective months of the program to identify the consumption response to the subsidy. Our empirical specification includes vehicle model fixed effects to account for time-invariant, model-specific, unobserved factors. Because this policy program builds up by releasing lists of subsidized models sequentially and unexpectedly, we are less worried about unobserved time variant factors related to specific subsidized models. Furthermore, we are able to control for time variant shocks to subsidized vehicles by using unsubsidized vehicles to construct relevant comparison groups.

A simple 'difference-in-differences' set-up may overestimate the true effect of the program if consumers who purchased subsidized vehicles merely substituted across vehicles with similar attributes or across time periods by delaying making purchases right before the program started. We explore these substitution effects by looking at substitution patterns of close substitutes and by creating a pre-event window to implement our 'difference-in-differences' set-up. We also complement our analysis with an event study analysis to show substitution patterns across different types of vehicles and time periods.

Our results suggest that the program boosted sales for subsidized vehicle models. We find that the share of marginal consumers subsidized by the program is nearly $47 \%$. Thus, about $53 \%$ of the program's payments were ineffective and distributional. We also discover that some of the increase in sales of the subsidized models was driven by a substitution 
effect within vehicle models, and that the substitution effect was not from gas-guzzlers to highly fuel efficient models, but rather was within highly fuel efficient models. We do not find evidence supporting an intertemporal substitution pattern. Using our estimates, we conduct a cost-benefit analysis and find that the program was an expensive way to reduce carbon dioxide emissions: the implied cost of a metric ton's reduction in carbon dioxide was 82 USD.

Adopting the framework in Boomhower and Davis (2014), which accounts for the presence of inframarginal consumers, but treats only the cost of raising governmental funds as the cost of the program, we find that the marginal cost of the program exceeds the marginal benefit by almost as much as 300 percent. This is true even when we account for the local pollution benefits from the program. Finally, we show that the program was not well targeted. In fact, the sales response of the program was smaller in areas where consumers were more likely to purchase relatively fuel inefficiency vehicles or were lower educated.

Our paper builds on the existing literature that evaluates the consumption response to energy efficient programs (Chandra, Gulati, and Kandlikar, 2010; Gallagher and Muehlegger, 2011; Boomhower and Davis, 2014; Houde and Aldy, 2014; Ito, 2015). ${ }^{3}$ Several studies point out that most of the consumers who receive subsidies are inframarginal. Mian and Sufi (2012) show that counties in the U.S. that were more exposed to the 2009 "Cash for Clunkers" program faced lower vehicle sales in the 10 months after the program expired, thus offsetting most of the initial sales response. Chandra, Gulati, and Kandlikar (2010) note that sales of high performance cars are crowded out as a result of subsidizing hybrid cars.

This paper differs from the previous literature by exploiting the variation in eligibility status created by the government's announcements in order to identify the share of marginal consumers who bought subsidized vehicle models and the extent to which subsidies created substitution among vehicles. To the best of our knowledge, our paper is the first empirical

\footnotetext{
${ }^{3}$ For recent studies that evaluate the effect of vehicle taxes on reducing fuel consumption and carbon dioxide emissions, see Xiao and Ju (2014) and Klier and Linn (2015). For studies that look at automakers' responses to energy efficient regulations or subsidies, see Sallee and Slemrod (2012) and Ito and Sallee (2014).
} 
study to evaluate the effect of China's energy efficient program on vehicle sales. Because China has become the largest global vehicle market and the biggest carbon dioxide emitting country and as subsidizing fuel efficient cars has been very popular in China since 2010, it is important to evaluate the effect of the subsidy program at its beginning stage. ${ }^{4}$

This paper proceeds as follows. We begin by discussing China's automobile industry, major vehicle regulations, details of the fuel efficient program, and the data. We then describe the empirical strategy and the corresponding estimating procedures. Finally, we present the empirical results and discuss the implications of the fuel efficient program.

\section{Industry and the Subsidy Program}

\subsection{Industry Background}

Ever since the implementation of the "reform and open" policies of the 1980s, China's automobile market has grown rapidly. In order to satisfy domestic demand for quantity, product quality, and variety and to accelerate industry upgrading and to bolster economic growth, in 1994 the State Council chose the automotive industry as one of the pillars of the economy and aimed to strengthen investment directed into it. At the same time, the National Development and Reform Commission (a subsidiary of the State Council) issued the Policy on Development of Automotive Industry (PDAI) giving priority to foreign investors with advanced technologies to create joint ventures with SOEs (state-owned enterprises). ${ }^{5}$ Attracted by these policies, most global car manufacturers began to establish joint ventures in China, and after China's entrance into the World Trade Organization (WTO) the number of them surged eve further. With the boost in joint ventures, vehicle sales stepped up from 1.34 million in 1994 to 19.31 million in 2012. Since 2009, China has become the largest global vehicle market with current annual sales of passenger cars exceeding 20 million.

\footnotetext{
${ }^{4}$ The government of China has launched another subsidy program for new-energy cars in most of its major cities since 2013 .

${ }^{5}$ Details of the policy can be found at: http://www.lawinfochina.com/display.aspx?lib=law\&id= 3556\&CGid=.
} 
While celebrating the success of the automotive industry's development, China has experienced the same consequences as countries experiencing increasing automobile demand: traffic congestion and air pollution. For example, according to China's Ministry of Environmental Protection (Ministry of Environmental Protection, 2010), vehicle emissions have become the main source of air pollution in cities of China, large and medium alike. In the World Health Organization's report on road safety (World Health Organization, 2013), China is ranked number one in the reported number of road traffic deaths in the last decade.

Various policies have been implemented at different government levels to mitigate the negative impacts on the environment from the development of the automobile industry. A few studies have evaluated their effectiveness. For instance, the central government applied tax policies (such as a fuel tax and a consumption tax (Xiao and Ju, 2014)) to control the size of the vehicle fleet and subsidy policies (as in our current study) to induce a switch in consumers' choice toward fuel efficient vehicles. Some local governments employ more stringent policies such as car usage restrictions, e.g. Beijing applied the "odd-even license plate rule" (Wang et al., 2009; Viard and Fu, 2015; Chen et al., 2013), or car ownership restrictions, e.g. the vehicle quota system (VQS) in Shanghai (Xiao et al., 2015; Li, 2015) and Beijing (Li, 2015; Hu et al., 2015).

The studies listed above have shown that a tax policy and car ownership restrictions can effectively restrain the growth of the vehicle fleet, and that car usage restrictions can markedly reduce pollution during the relevant restriction period. However, it should be noted that while the car restriction policies implemented in Shanghai and Beijing have proved useful in reducing vehicle sales, they have also shifted consumers' purchasing propensity toward low fuel efficient cars (Xiao et al., 2015; Hu et al., 2015). In this paper we study the implementation of subsidies for fuel efficient vehicles, but note that concurrent car ownership restrictions in Beijing and Shanghai will scale down consumers' response to the subsidy in these two cities. Therefore, the issue of concurrent policies needs to be addressed and carefully handled in our estimation. 


\subsection{The Cash Subsidy Program}

On June 18, 2010, China's central government launched a national incentive program for fuel efficient cars (henceforth "the program") that provided a one-time 3000 RMB (455 USD) cash subsidy to any consumer who purchases a government certified fuel efficient vehicle. ${ }^{6}$ To qualify for the program, car manufacturers must submit applications for their vehicles. After receiving an application for a particular vehicle model, the government would verify its attributes and decide whether the vehicle model is eligible. The average manufacturer's suggested retail price (MSRP) of eligible cars in 2010 (before the program) was 91,813 RMB, and so the subsidy was about a $3.3 \%$ discount off MSRP. The program became very popular, subsidizing more than 4 millions cars and paying out more than 12 billion RMB by the end of 2011.

The program had several distinct features. First, the eligibility status was an explicit function of vehicle attributes. The program only subsidized passenger cars with an engine size (displacement level) less than or equal to 1.6 liters. Any vehicle with an engine size greater than 1.6 liters, regardless of its fuel efficiency status, was excluded from the program. The government also laid out fuel efficiency thresholds used in the program, which take into account a vehicle's weight, transmission method (manual or automatic), and seating (two rows or three rows). Specifically, two-row vehicles equipped with manual transmission were subject to a stricter fuel efficiency standard (cutoff 1) than that faced by the rest of the vehicles (cutoff 2). To show this distinction, we plot eligibility cutoffs in Figure 1, with dashed and solid lines representing eligibility cutoff 1 and cutoff 2, respectively. As shown in the figure, the program cutoffs are step functions of vehicle curb weights, and vehicles that face cutoff 1 are regulated under higher standards at any given weight.

The second distinct feature of the program is that the effective date and the duration of

\footnotetext{
${ }^{6}$ Car dealers must affix an official program sticker to the side window of every program eligible vehicle. A consumer who purchases such a program eligible vehicle receives a fixed 3000 RMB discount off the agreed-upon transaction price from the dealer. The government then reimburses car dealers on a monthly basis.
} 
the subsidy for that particular model are not clear to manufacturer or consumers, even for a vehicle model that qualifies for the program's eligibility rule at the beginning of the program. The government only periodically announced a complied list of eligible vehicle models, and at any given time, little information was known regarding whether the government would continue or terminate the program in the future. During June 18, 2010 to October 17, 2011, the government released 7 official lists of eligible models, effectively creating 7 waves of subsidies.

The initial six waves of subsidies were cumulative, such that the number of subsidized vehicles was increasing as the program expanded over time. However, the 7th list adopted a set of stricter fuel efficiency thresholds that excluded nearly all vehicle models from the previous six lists. The government announced the 8th list of eligible models on July 10, 2012 and finally terminated the program on September 30, 2013. It reopened a new subsidy program with higher fuel efficiency standards on September 3, 2014.

\section{Data}

We obtain monthly sales data of passenger cars at the province level for new vehicle models produced and sold in China during 2007 to 2011..$^{7}$ The sales data include information regarding a vehicle model's identification code, type (indigenous, European, Japanese, Korean, or U.S.), identity of the manufacturer, vehicle category (small, medium, luxury, etc.), and engine size. We accompany sales data with vehicle attributes collected from other sources. Information regarding a vehicle's MSRP, power, and physical size is obtained from several leading websites that report new car attributes in China. ${ }^{8}$ Vehicle model level fuel inefficiency, curb weight, and program eligibility are public data from the Ministry of Industry and Information Technology's website. Using a vehicle's identification code, we match its

\footnotetext{
${ }^{7}$ All vehicles are passenger cars purchased by individuals for personal use. Data are obtained through private arrangement. To protect the proprietary information of the data provider, we cannot release the data source.

${ }^{8}$ We look for vehicle attributes on three websites: Sohu.com (http://auto.sohu.com/), Yiche.com (http://beijing.bitauto.com/), and Autonet (http://www. wwwauto.com.cn/clgl/index3.htm).
} 
model attributes and program eligibility to monthly sales in a province. After adjusting the number of days in a month that a vehicle was eligible for a subsidy, we identify 3.62 million vehicles subsidized in the first six waves. ${ }^{9}$ This estimate is consistent with reports by IBTS Investing Consulting Company (2012) that the total amount of vehicles subsidized in the first six waves was 3.57 million vehicles.

We also calculate the quartiles of each vehicle attribute for models sold in a given year. Demographic data at the province level, such as education levels, rural population, and average wage, are obtained from China Statistical Yearbook 2011. Finally, we collect information regarding the maximum retail gasoline prices allowed for Beijing from the National Development and Reform Commission to construct a proxy variable for gasoline expenditure per $100 \mathrm{~km}$ for each vehicle model during the time periods studied in this paper. ${ }^{10}$

Because official fuel inefficiency data are only available after 2010, most vehicle models sold before 2009 are missing fuel inefficiency values. As a result, our empirical analysis focuses on vehicle models sold between 2009 to 2011; data before 2009 are only used to identify the month a vehicle was first introduced to the market. ${ }^{11}$ The final sample in this paper includes vehicle sales during 36 months and across 31 provinces, for a total of 1115 markets. ${ }^{12}$ As discussed earlier, Shanghai and Beijing have strict vehicle licensing restrictions, and the consumption response in these two cities is likely to be different from that in other cities. The government also suddenly raised fuel efficiency standards of the program and stopped subsidizing most of the previous eligible vehicles in the 7th wave, introducing another layer

\footnotetext{
${ }^{9}$ Because the announcements of each wave of subsidies were made in the middle of a month and our data are at the monthly level, we are not able to calculate the exact number of vehicles subsidized for the first months of each new wave.

${ }^{10}$ The maximum retail gasoline prices in several provinces or major cities were regulated by the central government. During the 3-year period studied in this paper, the central government adjusted the maximum retail gasoline prices allowed for these areas simultaneously 15 times, but the amount of adjustments varied across the country.

${ }^{11}$ For each model sold between 2009 and 2011, we look for the first month of the sample that a vehicle model appears in the data and accordingly construct its age (the number of months in the market) and indicator variables for its birth quarters. For vehicles that seem to be manufactured in the first month of 2007, we record their product life cycle variables as missing values.

${ }^{12}$ Sales data for Qinghai Province in October 2010 are missing.
} 
of complexity into the program's effect on vehicle sales. To deal with these complexities, the sample in our main analysis excludes data from these two cities and the 7th wave. We discuss results that include data from Shanghai, Beijing, and the 7th wave in section 5.5.

\subsection{Program Eligibility}

Figures 2 and 3 plot fuel inefficiency and curb weights for gasoline vehicle models identified by the data to be eligible (subsidized) and ineligible for the program, respectively. In both figures, a hollow or a solid circle represents a vehicle with an engine size less or equal to 1.6 liters and is associated with cutoff 1 or cutoff 2, respectively. In Figure 3, a cross indicates a vehicle with an engine size greater than 1.6 liters and thus cannot qualify for a subsidy, regardless of its fuel efficiency status. ${ }^{13}$ As shown in both figures, there is a strong positive relationship between a vehicle's weight and its fuel inefficiency, but the variation in fuel inefficiency conditional on vehicle weight remains. In addition, eligibility status was "correct" in most cases: all eligible models (Figure 2) had their fuel inefficiency levels below their associated cutoffs, and most ineligible models (Figure 3) had higher fuel inefficiency than their cutoffs, with few exceptions. ${ }^{14}$

We also find that eligible vehicles, in addition to being more fuel efficient, tended to be more expensive than their peers. Columns (1) and (2) of Table 1 list means of sales and various attributes for eligible and ineligible models, respectively, with differences shown in column (3). All models in the table have an engine size less than or equal to 1.6 liters and were already in the market before the first wave of the program. On average, eligible vehicles had higher average province-model sales, were priced at 14,937 RMB higher, had larger values in horsepower, size, and weight, and were less likely to be indigenous brands than their

\footnotetext{
${ }^{13}$ During the time period of this study, almost all vehicles were powered by gasoline (99\%), followed by diesel $(0.5 \%)$, and gasoline/CNG $(0.2 \%)$. There were more than 2,000 models that were ineligible for the program. To make the graph more presentable and because manufacturers may be less likely to file applications for models that were going to be discontinued, we exclude vehicles with national sales less than 500 units in the sample to construct Figure 3.

${ }^{14} \mathrm{~A}$ violation of the eligibility rules occurs when a solid dot is above (below) the solid line, or when a hollow dot is above (below) the hollow line in Figure 2 (3). Violations could happen if a manufacturer did not submit applications for its models.
} 
peers, suggesting that the program was not designed to favor indigenous brands per se. We examine the relationship between vehicle price and eligibility by regressing vehicle price on eligibility status and other attributes. Columns (4) and (5) of Table 1 give results from price regressions that include country fixed effects and manufacturer fixed effects, respectively. After controlling for manufacturer fixed effects and other attributes, we find that a vehicle's eligibility was not associated with its price, suggesting that on average eligible products did not exhibit superior or inferior unobserved product attributes.

We now turn to the program eligibility across time. Table 2 provides the release dates of the 7 waves of subsidies, along with the number of new vehicle models added to the pool of subsidized models. Because the number of subsidized models was accumulated over the first 6 waves, there was a total of 423 vehicle models eligible for the subsidy by the end of the program's 6th wave and 262 of them were identified in the sales data. However, only 19 new vehicle models became eligible after the 7 th wave of the program due to stricter fuel efficiency standards. In addition, only 30 models from all previous lists remained subsidized in the 7 th wave, shrinking the total number of eligible models from 423 to 49 . Because the lists were mostly released in the middle of a month, we exclude observations from months in which a new wave of subsidies began to take place for our main results. We provide estimation results for the first month when we examine intertemporal substitution patterns with an event study design.

Table 2 also tabulates the country of origin of eligible models for each list. As shown in the table, most eligible cars are China's indigenous products. Nevertheless, joint venture manufacturers producing European, Japanese, Korean, or U.S. models also enrolled some of their models into the program. Out of the total 442 models that became eligible for subsidies during 2010 and 2011, we are able to match 263 models with the sales data. ${ }^{15}$ We find that 150 models of these models were launched into the market only after they became eligible

\footnotetext{
${ }^{15}$ Our dataset includes only pure passenger cars from 2007 to 2011 . For those 179 models that were not identified in our sales data, 50 of them were small multi-purpose cars (used for small business). It is possible that some of the remaining unidentified vehicles were never launched into the market or launched in 2012.
} 
for the program, leaving a total of 113 models with sales observations both before and after they received their subsidies.

\subsection{Summary Statistics}

Panel A of Table 3 provides summary statistics for the main variables at the vehicle level in the final sample. The average monthly sales number for a vehicle model in a province is 36 . The average engine size, fuel inefficiency, gasoline expenditure, horsepower, and weight are 1.8 liters, 8 liters per 100 kilometers, 50 RMB per 100 kilometers, 93 kilowatts, and 1345 kg, respectively.

To explore whether the program targeted consumers who were more likely to buy fuel inefficient models, we use data before the first wave to calculate the share of vehicles sold in a province that were fuel inefficient. We classify a vehicle as fuel inefficient if its fuel inefficiency and weight combination is above the bivariate regression fitted line, i.e., conditional on its weight level, its fuel inefficiency is above the conditional mean. We use this variable to examine whether the program's effect on increasing the sales of fuel efficient vehicles was stronger in provinces where consumers were more likely to purchase fuel inefficient vehicles. We use this as a measure of whether the program was well-targeted.

Panel B of Table 3 provides summary statistics for variables at the province level. There is large variation across provinces for demographic variables. For example, the share of population with a high school degree ranges from $10.95 \%$ (Tibet) to $54.96 \%$ (Beijing), and the average wage per year ranges from 27,735 RMB (Heilongjiang) to 66,115 RMB (Shanghai). The average, minimum, and maximum shares of fuel inefficient vehicles sold were $39 \%$, $35 \%$ (Heilongjiang), and 48\% (Qinghai), respectively.

\subsection{Graphical Evidence}

Figure 4 gives total national vehicle sales from January 2009 to December 2011. As shown in Figure 4(a), total vehicle sales for all vehicles seem to follow similar monthly trends both 
prior to and during the program. December was the highest grossing month, and the month with the Chinese New Year (February or sometimes January) was the lowest selling month. If we focus on the sales of vehicles of 1.6 liters or below with positive sales before the subsidy program (Figure 4(b)), we find that ineligible cars had higher sales than eligible ones in general, but the gap became much smaller after the program was implemented.

Figure 5 plots the time series of sales-weighted average vehicle attributes (fuel inefficiency, weight, horsepower, and price) by vehicle engine size. Average fuel inefficiency decreased from 7.26 (liters $/ 100 \mathrm{~km}$ ) to 6.88 (liters $/ 100 \mathrm{~km}$ ) for vehicles with engine size less than or equal to 1.6 liters during this period of time, but appears more stable for vehicles with a larger engine size (from 8.79 liters per $100 \mathrm{~km}$ to 8.7 liters per $100 \mathrm{~km}$ ). We do not find decreasing trends in other vehicle attributes. If anything, we find evidence of upward trends in vehicle weight, horsepower, and price, suggesting that consumers did not substitute these attributes for lower fuel inefficiency. Many factors may have contributed to the increase in sales and average fuel economy of smaller vehicles, including the subsidy program. In our empirical analysis, we aim to quantify the effectiveness of the program by looking at the sales response to the program in a difference-in-differences setting and examining the substitution effect across vehicle types.

\section{Empirical Strategy}

We adopt a 'difference-in-differences' approach to study the extent to which subsidized vehicle models were purchased by marginal consumers. Our empirical investigation compares sales of subsidized models before and after receiving subsidies to sales of models that were never subsidized, but were sold during the same periods of time. We explore the choice of the comparison group in two steps. First, all models that were not eligible for subsidies are used as the comparison group. Second, we consider the case when vehicles with similar attributes may suffer from the substitution effect and only use "poor substitutes" to construct the comparison group. 
To begin with, we fit the data using the following specification:

(1) $\ln$ Sales $_{i j t}=\mu+\alpha_{i}+\alpha_{j}+\alpha_{t}+\beta 1$ (Receiving a subsidy) ${ }_{j t}+\gamma G a s_{j t}+X_{j t} \delta_{1}+Z_{j t} \delta_{2}+\epsilon_{i j t}$.

Here, $\ln$ Sales $_{i j t}$ is the natural $\log$ of monthly sales for model $j$ in province $i$ during month $t$. In addition, $\mu$ is a constant, and $\alpha_{i}, \alpha_{j}$, and $\alpha_{t}$ are the province, vehicle model, and month-of-sample fixed effects, respectively. The indicator variable 1 (Receiving a subsidy) ${ }_{j t}$ takes a value 1 when a vehicle model $j$ is subsidized during month $t$ and 0 otherwise. The $\beta$ coefficient provides an estimate of a subsidy on vehicle sales under a 'difference-in-differences' setting with multiple events. The larger the $\beta$ coefficient is, the stronger is the effect of the program on inducing marginal consumers to buy fuel efficient models. Gas $s_{j t}$ is the gasoline expenditure per 100 kilometers, i.e., the product of gasoline price per liter and fuel inefficiency per 100 kilometers. We also include two sets of control variables, $X_{j t}$ and $Z_{j t}$, that take a vehicle model's product life cycle and vehicle category time trends into account. The variables in $X_{j t}$ are interaction terms between a vehicle model's age and indicator variables for its birth quarter, as well as interactions between its squared age and indicator variables of birth quarters. The variables in $Z_{j t}$ are time trends and squared time trends specific to vehicle categories. ${ }^{16}$

Under the assumption that all increased sales of eligible models were drawn from consumers whose first choice was an outside good (i.e., no substitution effect between new vehicles), the results from equation (1) give the program's true effect on increasing sales of subsidized models. However, if some of the increased sales of eligible models were lost sales diverted from other models in the comparison group, then estimates from equation (1) would overestimate the true effect of the program. Our interpretation is that the results from equation (1) provide an upper bound of the program's effect on boosting sales of subsidized cars.

\footnotetext{
${ }^{16}$ There are eight vehicle categories, including micro, small, medium, standard, luxury, sport, multipurpose, and sport utility vehicle.
} 
We deepen our analysis by examining both the substitution patterns across vehicle attributes and over time resulting from the subsidy program. If consumers who purchased program eligible vehicle models merely substituted between models with similar attributes, then we would expect the $\beta$ coefficient of equation (1) to be larger when we included those close substitutes in the comparison group. Similarly, consumers could postpone buying vehicles right before the first wave, because they had heard the news about this new national subsidy program, creating a substitution effect over time. To explore the substitution pattern across vehicle attributes, we locate the attribute quartiles of each vehicle for several attributes, including fuel inefficiency, engine size, and weight. We also construct a threemonth pre-event window to detect the effect from delaying purchases.

We next estimate the following equation:

$$
\begin{aligned}
& \ln \text { Sales }_{i j t}=\mu+\alpha_{i}+\alpha_{j}+\alpha_{t}+\beta 1(\text { Receiving a subsidy })_{j t} \\
& \quad+\beta_{1} 1(\text { Unlisted })_{j} \times 1(\text { Post })_{t} \times 1(\text { Attribute quartile }=1)_{j} \\
& \quad+\beta_{2} 1(\text { Unlisted })_{j} \times 1(\text { Post })_{t} \times 1(\text { Attribute quartile }=2)_{j} \\
& \quad+\beta_{3} 1(\text { Unlisted })_{j} \times 1(\text { Post })_{t} \times 1(\text { Attribute quartile }=3)_{j} \\
& \quad+\beta_{4} 1(\text { Post })_{t} \times 1(\text { Listed but not subsidized yet })_{j t}+\beta_{5} 1(\text { Pre })_{t} \times 1(\text { Close substitutes })_{j} \\
& \quad+\gamma \text { Gas }_{j t}+X_{j t} \delta_{1}+Z_{j t} \delta_{2}+\epsilon_{i j t} .
\end{aligned}
$$

Here, 1 (Post) $)_{t}$ is an indicator variable for all time periods after the first wave; 1 (Attribute quartile $\left.=k\right)_{j}$ is an indicator variable for vehicles in the $k$ th attribute quartile; 1 (Unlisted) ${ }_{j}$ is an indicator variable for vehicles that were not listed in any of the 7 waves of the subsidy; and 1 (Listed but not subsidized yet) ${ }_{j t}$ is an indicator variable for vehicles that were listed in one of the 7 waves and time periods before their wave of subsidy kicked in. In this model, we use vehicles that were never subsidized and in the fourth attribute quartile as the comparison group. 
More importantly, $\beta_{k}, k=1,2,3$, measures whether the program affects sales of unsubsidized vehicles in attribute quartile $k$. For example, a negative $\beta_{1}$ for fuel inefficiency (with the first quartile encompassing the most fuel efficient products) would suggest that the program created a substitution effect between highly fuel efficient models. To detect the delaying purchase effect, we construct an interaction term $1(\text { Pre })_{t} \times 1$ (Close substitutes ${ }_{j}$, where $1(\text { Pre })_{t}$ and 1 (Close substitutes) ${ }_{j}$ are indicator variables for the 3 -month pre-event window (March 2010 to May 2010) and all vehicles not in the comparison group, respectively, and so a negative $\beta_{5}$ would suggest the existence of the delaying purchase effect. If substitution effects are prevalent, then our estimated coefficient of equation (1) would overestimate the true effect of the program.

The setting in equation (2) uses the three-month pre-event window to detect an intertemporal substitution effect before the program took place. In fact, we can directly examine the entire intertemporal substitution patterns before, during, and after the program by estimating the following event study specification:

$$
\begin{aligned}
& \left.\ln \text { Sales }_{i j t}=\mu+\alpha_{i}+\alpha_{j}+\alpha_{t}+\sum_{m=-12}^{15} \beta_{m} 1 \text { (Number of months being subsidized }=m\right)_{j m} \\
& \left.+\sum_{m=-12}^{15} \beta_{1 m} 1 \text { (Number of months after 1st wave }=m\right)_{m} \times 1(\text { Attribute quartile }=1)_{j} \times 1(\text { Unlisted })_{j} \\
& +\sum_{m=-12}^{15} \beta_{2 m} 1(\text { Number of months after 1st wave }=m)_{m} \times 1(\text { Attribute quartile }=2)_{j} \times 1(\text { Unlisted })_{j} \\
& +\sum_{m=-12}^{15} \beta_{3 m} 1(\text { Number of months after } 1 \text { st wave }=m)_{m} \times 1(\text { Attribute quartile }=3)_{j} \times 1(\text { Unlisted })_{j} \\
& \quad+\gamma \text { Gas }_{j t}+\epsilon_{i j t} .
\end{aligned}
$$

The variables 1 (Number of months being subsidized $=m)_{j m}$ are indicator variables for the number of months that had elapsed since a vehicle model acquired its program eligibility status. Similarly, 1 (Number of months after 1st wave $=m)_{m}$ are indicator variables for 
the number of months that had elapsed since the first wave. ${ }^{17}$ In addition, to show sales trends before and after the events, we exclude control variables of product life cycle and category trends. As the program went on, negative values of $\beta_{m}$ should provide evidence of intertemporal substitution for subsidized products. All standard errors are clustered at the vehicle model level.

\section{Results}

\subsection{Effect of the Program on Sales of Subsidized Models}

Table 4 provides estimation results for the coefficient of 1 (Receiving a subsidy) ${ }_{j t}$ using equation (1) and data from the first six waves (January 2009 to September 2011). Column (1) of Table 4 gives the baseline results, while columns (2) and (3) provide further results that include additional control variables. In the baseline setting, the estimated coefficient of 1 (Receiving a subsidy) ${ }_{j t}$ is 0.668 and is statistically significant. In columns (2) and (3), we include additional control variables to absorb variation due to a model's product life cycle and category specific trend. The estimated coefficients are both significant and are 0.652 and 0.684 , respectively. The estimated coefficients of gasoline expenditure are positive in columns (1) and (2), but once we include control variables for category trends, the coefficient of gasoline expenditure becomes negative and cannot be estimated with precision. Overall, the pattern emerging in Table 4 suggests that the program boosted sales for subsidized vehicle models.

\subsection{Substitution Across Vehicle Attributes or Time Periods}

We then examine whether part of the increased sales of subsidized models resulted from substitution effects between models with similar attributes or time periods. Columns (1) and (4) of Table 5 provide the estimation results of equation (2), with the vehicle attribute

\footnotetext{
${ }^{17} \mathrm{~A}$ negative value of $m$ indicates the number of months before the event. Because the base month we use is one month before the event, $m=-1$ actually indicates 2 months before the event, and $m=-12$ indicates all months that are 13 months (or more) before the event.
} 
used for estimation being fuel inefficiency, including and excluding the interaction term of the pre-event window and close substitutes, respectively. The estimated coefficients in columns (1) and (4) of 1 (Receiving a subsidy) ${ }_{j t}$ are 0.659 and 0.625 , respectively, which are lower than those coefficients estimated in Table 4. In our preferred setting with all control variables (column (4)), the estimated coefficient of 1 (Receiving a subsidy) ${ }_{j t}$ implies that subsidizing a vehicle increased the vehicle's sales by $86.8 \%((\exp (0.625)-1) \times 100 \%)$, and so the share of marginal consumers among all subsidy recipients for the first six waves was $46.5 \%(0.868 /(1+0.868) \times 100 \%)$.

More importantly, in columns (1) and (4), we find that the coefficient associated with the interaction terms of the first fuel inefficiency quartile and the implementation of the program is negative and significant, while the coefficients associated with the second and the third quartiles are much smaller and insignificant. Therefore, we do not find evidence supporting the program's effect on decreasing sales of highly fuel inefficient vehicles. By contrast, our results suggest that the program decreased sales of vehicles that were the least fuel inefficient. The coefficient of the interaction between the 3-month pre-event window and close substitutes (all vehicles that were not in the fourth quartile of fuel inefficiency) is negative but insignificant in column (4). In addition, we find that the coefficients of 1 (Post) $)_{t} \times 1$ (Listed but not subsidized yet $)_{j t}$ in both columns (1) and (4) are not significant. Therefore, even after the first wave, consumers did not postpone buying future would-besubsidized vehicles, most likely because the continued subsidy of these vehicles was not predictable to consumers.

We further provide estimation results of equation (2) using engine size and weight as vehicle attributes in the rest of Table 5. The comparison groups are vehicles in the fourth quartiles of engine size (columns (2) and (5)) and weight (columns (3) and (6)). Again, we find that the program had a negative and significant impact on the sales for vehicles that were never subsidized and were in the first or the second quartiles of vehicle engine size or weight. Summarizing our results, we find that the program increased vehicle sales for subsidized 
products but decreased sales for vehicles that were smaller in engine size, less heavy, and more fuel efficient, without creating any significant substitution effect from vehicles in the third attribute quartiles. The revealed substitution patterns suggest that most of marginal consumers' original choices were smaller or fuel efficient models, and thus estimates without considering the substitution effect would be too optimistic about the program's effect.

\subsection{Intertemporal Substitution}

This subsection presents results from an event study setting to show the full path of the program's impact on subsidized and unsubsidized products. The event study setting is particularly useful to detect intertemporal substitution patterns. If most of the marginal consumers we identified during our data window were in fact inframarginal consumers in a longer time window, then our previous results would overestimate the true effect of the program. In this case, examining consumers' purchasing pattern over time would give us a more complete picture of the program.

Figure 6 plots the estimated coefficients corresponding to the subsidized vehicles $\left(\beta_{m}\right)$, along with their $95 \%$ confidence intervals for equation (3), using the data window from January 2009 to September 2011 and vehicle fuel inefficiency to construct the comparison group. Notice that in this set-up, we do not include control variables for product life cycles and vehicle category trends in the regression. The base month is the month right before a vehicle model started to receive its subsidy. For coefficients associated after a vehicle received its subsidy, we find that the estimated coefficient is smallest for the month in which a new wave of subsidy took place (month "zero" in Figure 6), which is most likely due to the fact that all of the release dates were not at the beginning of a month. The estimated coefficients for months after the first month are never negative and significant, and so we do not find evidence supporting intertemporal substitution within eligible models as in Mian and Sufi (2012).

Figures 7, 8, and 9 give the estimated coefficients for unsubsidized vehicles from the first 
$\left(\beta_{1 m}\right)$, the second $\left(\beta_{2 m}\right)$, and the third $\left(\beta_{3 m}\right)$ attribute quartiles, respectively. Unlike Figure 6 , in which the event months are time periods when a new wave of subsidy took place, the event month (month "zero") in these three figures is the beginning of the first wave, i.e. June 2010. Looking at these graphs, we find that sales of unsubsidized vehicles from different fuel inefficiency quartiles share a similar pattern before the program took place in June 2010. We also find that the sales of unsubsidized vehicles in the lowest quartile were decreasing after the program took place, confirming the substitution effects identified in previous analysis. We find no significant negative impacts on the sales of vehicles in the second and third attribute quartiles after the program took place.

\subsection{Share of Inefficient Models and Program Participation}

One of the main motivations for energy efficient programs is to address asymmetric information and behavior biases: if some consumers do not have enough information or cannot recognize the benefits of fuel efficient products in the long run, then subsidizing fuel efficient products can be welfare improving. This subsection examines whether the fuel efficient program was effective at targeting those consumers. Specifically, we test whether the effects of the program were stronger in areas where shares of consumers who purchased relatively fuel inefficient models were higher. ${ }^{18}$ We test this hypothesis by interacting (Share of fuel inefficient models) ${ }_{i}$ with 1 (Receiving a subsidy) ${ }_{j t}$ and 1 (Unlisted $)_{j} \times 1$ (Post) ${ }_{t} \times$ 1(Attribute quartile $=k)_{j}, k=1,2,3$ in equation (2) and keeping all the control variables. In this specification, a positive and significant coefficient on the interaction term between receiving a subsidy and (Share of fuel inefficient models) ${ }_{i}$ provides evidence that the program was effective at targeting marginal consumers who were more likely to purchase fuel inefficient models. In another specification, we include additional interaction terms constructed from demographic variables, including the share of high school degrees, the share of rural population, and average wage.

\footnotetext{
${ }^{18}$ As discussed in the previous section, we define a vehicle model to be fuel inefficient if its fuel inefficiency is higher than the conditional mean based on its weight.
} 
Table 6 presents the estimation results. In both columns (1) and (2), the estimated coefficients of variables interacting with (Share of fuel inefficient models) ${ }_{i}$ tend to have opposite signs compared to their main effect (i.e., without the interaction term) and so offset their main effects. In particular, the estimated effect on subsidized vehicles was lower in areas where the share of consumers buying fuel inefficient models was higher. Moreover, the results in column (3) show that the increase in sales of subsidized models was higher when the percentage of those with a high school degree was also higher, indicating that the program did not target low-educated consumers very well. These results show that the program was not effective at targeting consumers who were more likely to suffer from asymmetric information or behavior biases and therefore would be more likely to buy fuel inefficient vehicles. We show that overall the program created a substitution effect between smaller and highly fuel efficient models, that most of the subsidies went to inframarginal consumers, and that provinces with a higher share of fuel inefficient vehicles and low-educated consumers were less likely to have marginal consumers of the subsidy program.

\subsection{Robustness Checks}

All estimates reported above are obtained by excluding observations from Shanghai and Beijing in our regressions. Because the two cities have implemented strict licensing restrictions on new vehicles since 2000 and 2011, respectively, the effect of the subsidy program depends on interactions between these two policies. With the presence of licensing restrictions, marginal consumers of the subsidy program were those who were able to obtain a vehicle license and would switch their choice of vehicles based on a cash subsidy. Therefore, the effects of the subsidy program in Shanghai and Beijing were likely to be dampened. As a robustness check, columns (1) to (3) of Table 7 report results that include observations from Beijing and Shanghai. As expected, the estimated coefficients of 1 (Receiving a subsidy) ${ }_{j t}$ in columns (1) to (3) Table 7 are all smaller than those in Table 5.

Our main results use only the variation generated from the first six waves. In the 7 th 
wave, the eligibility threshold was stricter and few vehicles remained on the subsidized list. Columns (4) to (6) of Table 7 expand the data window to include the variation generated by the 7th wave and test whether stopping vehicle subsidies had any effect on vehicle sales. As shown in these columns, most of the qualitative results hold when we include data from the 7th wave, but we find that stopping a vehicle subsidy actually increased sales compared to vehicles in the comparison group. One potential explanation is that dealers may have continued to provide discounts or other promotions for these vehicles after their eligibility status was suddenly revoked, and so vehicle sales did not drop immediately after losing eligibility status.

Finally, our main results exclude samples from the first months in which a new wave of subsidy was launched, because policy announcements were often made in the middle of a month. As a robustness check, instead of excluding these months, we adjust the variables $(\text { Receiving a subsidy })_{j t},(\text { Post })_{t}$, and (Pre) $)_{t}$ in equation (2) to take into account the number of days in a month that a vehicle was eligible for a subsidy for each wave. We present the estimated results in Table 8, which shows qualitative results similar to those in our main findings.

\section{Cost-Effectiveness and Welfare Analysis}

\subsection{Implied Price of Gasoline and Carbon Dioxide Saved}

This subsection evaluates the program's cost effectiveness by calculating the implied price of gasoline and carbon dioxide saved from the program. We calculate the counterfactual sales when the subsidy program was not in place and compare them with observed sales after the program became effective. Using our estimates from Table 5 (column (4)), we know that the program increased sales of existing subsidized products by $86.8 \%$ and decreased existing unsubsidized products in the first vehicle fuel inefficiency quartile by $27.6 \%$. We then back out counterfactual sales from observed sales after the program became effective for these 
groups of vehicles. We make two assumptions for "new vehicles". For unsubsidized vehicles that were only available after the program became effective, we assume that the program only lowered their sales by $27.6 \%$ if and only if they were in the first fuel inefficiency quartile; and for subsidized vehicles that were only available after they received their subsidy, we assume that their observed sales were increased by $86.6 \%$ due to the program.

Table 9 summarizes our findings for the program's overall effect on total sales and fleet fuel inefficiency. Column (1) of Table 9 reports average fuel inefficiency by product attributes after the program became effective. Columns (2), (3), and (4) provide monthly observed sales before the program, after the program, and counterfactual sales after the program, respectively, while column (5) provides the difference between the observed sales and counterfactual sales after the program. Total vehicle sales and average fuel inefficiency across all products are also given in the last two rows of Table 9. We bootstrap across vehicle models to obtain standard errors (given in parentheses) for the program's effect on monthly sales and average fuel inefficiency. Under our assumptions about new vehicles, the program decreased the average fleet fuel inefficiency by 0.165 liters per 100 kilometers, and the effect was significant at the $10 \%$ level. The subsidy program also increased national monthly vehicle sales by 86,742 , even though this effect on sales could not be estimated precisely. The effect of such additional total vehicle sales would make a huge impact on the implied price of gasoline savings, which we will discuss later.

We then use estimated changes in average fuel inefficiency and total sales to calculate the implied prices of gasoline and carbon dioxide saved by the program. Because the current compulsory retirement requirement caps a vehicle's lifetime mileage at 600,000 kilometers, the maximum lifetime savings in gasoline consumption of an average vehicle are capped at $600,000 / 100 \times 0.165=990$ liters. ${ }^{19}$ If we fix total number of vehicles sold during this time at the counterfactual level, then the maximum lifetime savings of total gasoline during this time

\footnotetext{
${ }^{19}$ The compulsory retirement requirement of vehicles in China was a maximum lifetime of 10 years before May 2013 and is currently a maximum of vehicle mileage traveled of 600,000 kilometers.
} 
would be 5.8 billion liters. Given that the actual payment of subsidized vehicles during the same time (excluding the first months of each new wave) was around 7.39 billion RMB, or 1.12 billion USD, we find that for each liter of gasoline saved, the implied price is 0.193 USD per liter, or 0.731 USD per gallon. If we assume that each gallon of gasoline emits 8.9 kilograms of carbon dioxide, then the implied price of carbon dioxide of the program is approximately 82 USD per metric ton. Because we use the compulsory retirement requirement to calculate a vehicle's lifetime mileage with a zero discount rate under the assumption that the program did not generate any additional sales to obtain the above results, the savings in carbon dioxide are also clearly upper bounds, and the implied price should be interpreted as a lower bound.

Table 10 summarizes the calculated implied price of gasoline and carbon dioxide saved under different scenarios. As shown in columns (3) and (4) of Table 10, if we instead allow the possibility that the program created additional total vehicle sales as implied in Table 9 , then the implied price of carbon dioxide saved would be -17 USD per ton and -20 USD per liter under a $0 \%$ and $3 \%$ discount rate, respectively, suggesting that instead of subsidizing consumers to reduce carbon dioxide emissions, the government would in fact be subsidizing consumers to generate more carbon dioxide under these worst scenarios.

The current carbon price in China is less than $10 \mathrm{USD} /$ metric ton, and most countries in the world have a carbon price or tax less than $20 \mathrm{USD} /$ metric ton. ${ }^{20}$ Moreover, the current average social cost of carbon dioxide/metric ton estimated by the U.S. Environmental Protection Agency (EPA) is between 12 and 62 USD. ${ }^{21}$ Paying more than 82 USD for a metric ton of carbon dioxide is not a cost effective way to reduce carbon dioxide; if the main policy objective of China's subsidy program on fuel efficient vehicles was to reduce carbon dioxide emissions, then our results suggest that it was an ineffective way to achieve this goal.

\footnotetext{
${ }^{20}$ See Kossoy et al. (2000).

${ }^{21}$ See http://www.epa.gov/climatechange/EPAactivities/economics/scc.html.
} 


\subsection{Welfare Analysis}

This subsection evaluates the program's effectiveness in a broader context. We consider the program's effect on social benefits and social costs. For the program's impact on increasing social benefits, we consider the case in which a reduction in gasoline consumption is not only socially beneficial by lowering carbon dioxide emissions, but also by lowering local air pollution levels. Using the estimates from Parry et al. (2014), we assume that the marginal benefits from the reduction of air pollution and carbon dioxide in China are 0.05 and 0.08 USD per liter, respectively.

For the program's impact on creating social costs, we consider the efficiency costs from transfers and private costs from driving consumers away from their first choice of vehicles. Following Boomhower and Davis (2014), we use $(\eta-1)$ to denote efficiency loss from transfers and let the benchmark of $\eta$ be $1.3 .^{22}$ A higher $\eta$ represents a larger efficiency loss from transfers. If $\eta$ is one, then there is no efficiency loss from transfers. In addition, we assume that the demand for fuel efficient vehicles is linear, and so the average private cost per induced consumer can be approximated by $3,000 / 2=1,500$. Using the information from Table 5 , we calculate that $46.5 \%$ of subsidized consumers are marginal consumers, implying that the marginal social cost per inducement is 3,436 RMB. ${ }^{23}$ In addition, based on empirical findings in this paper, marginal consumers who purchased a subsidized vehicle had their original choices of vehicles reside in the lowest fuel inefficiency quartile, and so the average fuel inefficiency of their original choice set would be 6.7 liters per 100 kilometers, leading a saving of 0.201 liters/100 kilometers per inducement of subsidized vehicle.

\footnotetext{
${ }^{22}$ Consider the following welfare function: $W=U(Q(s))-C(Q(s))+\tau Q(s)-(\eta-1) Q(s) s$, where $Q$ is the number of adopters of fuel efficient products, and $s$ is the amount of subsidy. $U(Q(s))$ and $C(Q(s))$ are respectively the private benefits and costs from driving fuel efficient vehicles. $\tau$ is the external benefit from driving fuel efficient vehicles, and $\eta$ measures the efficiency loss from transfers.

${ }^{23}$ When the share of marginal consumers is $x$, the government must subsidize up to $1 / x$ consumers to generate one unit of an induced purchase. Among those $1 / x$ consumers, 1 of them is the marginal consumer, who incurs a 1,500 RMB efficiency loss (due to the deviation from her original optimal choice of vehicle), and all of them incur $(\eta-1) \times 3,000$ RMB efficiency loss from transfers. As a result, the social cost per inducement in this case is $(1.3-1) \times 3,000 \times(1 / x)+1,500 \mathrm{RMB}$.
} 
Table 11 provides the results from our welfare analysis under the assumption that the program created no additional total sales. Columns (3) and (6) give marginal benefits per inducement when discount rates are $0 \%$ and $3 \%$, respectively. The results in columns (3) show that even under the most optimistic scenario (a zero discount rate), once we take the substitution effect into account (the first row), the social marginal benefit per inducement (1,036 RMB) is less than the social marginal cost per inducement (3,436 RMB).

The above results are obtained by using $\eta=1.3$ and letting the marginal social benefit from reducing a liter of gasoline be 0.13. Columns (4) and (7) extend the analysis and calculate the maximum $\eta$ for the subsidy program to have a net social benefit. In addition, columns (5) and (8) provide the minimum social marginal cost from reducing a liter of gasoline for the program to be socially beneficial when $\eta$ is fixed at 1.3 . We find that when the discount rate is $3 \%$, the implied efficiency loss (0.904) needs to be much lower than the benchmark (1.3) for the program to be socially beneficial, and the minimum marginal tax of gasoline needs to be 0.506 (USD/liter) in order for the program to have a net social benefit (when $\eta$ is fixed at 1.3).

The second row of Table 11 reports results from welfare analysis when policymakers ignore the substitution effect within highly fuel efficient vehicles. In this naive case, the government assumes that a typical marginal consumer's original choice of vehicle was an "average" unsubsidized car, so that for each inducement, a typical marginal consumer's original choice of vehicle would be a vehicle with a higher fuel inefficiency level (8.09 liters per 100 kilometers in this case). Thus, the average savings per inducement in this case would be higher than that when the marginal consumer's original choice was also highly fuel efficient. Column (6) shows that when the discount rate is $3 \%$ and the gasoline savings are calculated from the national fleet average (all unsubsidized vehicles), the marginal social benefit per inducement is $6,963 \mathrm{RMB}$, which is larger than the marginal social cost per inducement. The program would seem even more beneficial if policy makers employ a higher share of marginal consumers than that found in this paper and a zero discount rate. Overall, 
our analysis shows that once we take the pervasiveness of inframarginal consumers and the substitution pattern into account, the program is cost ineffective in reducing carbon dioxide emissions and hardly welfare enhancing.

\section{Conclusion}

In this paper we examine the consumption response to China's subsidy program of fuel efficient cars within the first six waves of implementation. We show that around $53 \%$ of consumers who purchased eligible models were inframarginal and received additional cash simply by buying their original choice of vehicles, and that marginal consumers' original choice of vehicles was not gas-guzzlers. The presence of a large share of inframarginal consumers and the observed substitution pattern question the cost effectiveness of the program on reducing carbon emissions. We also find that the effect of the program was smaller in provinces where consumers were more likely to purchase fuel inefficient models, indicating that the program was not well-targeted.

It is important to note that our study focuses on the consumption response at the beginning of the program. Subsidizing fuel efficient cars remains a popular policy tool in China. The subsidy program studied in this paper was shut down in September 2013, but was reopened in September 2014. Moreover, since 2013, the government in China has launched another subsidy program for new-energy vehicles (mostly electric cars) in several major cities. The amount of the subsidy is large (can be up to 120,000 RMB per vehicle), and incidents of fraud from electric car manufacturers have been reported, prompting the government to investigate this issue. Further research is needed to examine manufacturers' response to fuel efficient programs in the long run. Finally, we find that the subsidy was slightly less likely to be taken up by marginal consumers in Beijing and Shanghai, where new car licenses were strictly regulated. The interaction of environmental policies remains an important issue to be explored. 


\section{References}

Allcott, H. and M. Greenstone (2012). Is there an energy efficiency gap? Journal of Economic Perspectives 26(1), 3-28.

Allcott, H., C. Knittel, and D. Taubinsky (2015). Tagging and targeting of energy efficiency subsidies. American Economic Review, Papers Proceedings 105(5), 187-91.

Boomhower, J. and L. W. Davis (2014). A credible approach for measuring inframarginal participation in energy efficiency programs. Journal of Public Economics 113, 67-79.

Borenstein, S. and L. W. Davis (2015). The distributional effects of U.S. clean energy tax credits. Working Paper 21437, National Bureau of Economic Research.

Chandra, A., S. Gulati, and M. Kandlikar (2010). Green drivers or free riders? An analysis of tax rebates for hybrid vehicles. Journal of Environmental Economics and Management $60(2), 78-93$.

Chen, Y., G. Z. Jin, N. Kumar, and G. Shi (2013). The promise of Beijing: Evaluating the impact of the 2008 Olympic games on air quality. Journal of Environmental Economics and Management 66(3), 424-443.

Gallagher, K. S. and E. Muehlegger (2011). Giving green to get green? Incentives and consumer adoption of hybrid vehicle technology. Journal of Environmental Economics and Management 61(1), 1-15.

Gillingham, K., R. G. Newell, and K. Palmer (2009). Energy efficiency economics and policy. Annual Review of Resource Economics 1(1), 597-620.

Houde, S. and J. E. Aldy (2014). Belt and suspenders and more: The incremental impact of energy efficiency subsidies in the presence of existing policy instruments. Working Paper 20541, National Bureau of Economic Research. 
Hu, W.-M., R. Szulga, and X. Zhou (2015). When is a random lottery not fair? The Beijing vehicle quota system and equal opportunity. Working paper.

IBTS Investing Consulting Company (2012). Industry dynamics: Fuel efficient subsidies in China. Technical report, Taipei, Taiwan.

Ito, K. (2015). Asymmetric incentives in subsidies: Evidence from a large-scale electricity rebate program. American Economic Journal: Economic Policy 7(3), 209-37.

Ito, K. and J. M. Sallee (2014). The economics of attribute-based regulation: Theory and evidence from fuel-economy standards. Working Paper 20500, National Bureau of Economic Research.

Klier, T. and J. Linn (2015). Using taxes to reduce carbon dioxide emissions rates of new passenger vehicles: Evidence from France, Germany, and Sweden. American Economic Journal: Economic Policy 7(1), 212-42.

Knittel, C. R. (2012). Reducing petroleum consumption from transportation. Journal of Economic Perspectives 26(1), 93-118.

Kossoy, A., G. Peszko, K. Oppermann, N. Prytz, A. Gilbert, N. Klein, L. Lam, and L. Wong (2000). Carbon pricing watch 2015 : An advance brief from the state and trends of carbon pricing 2015 report. Technical Report MSU-CSE-00-2, World Bank Group, Washington, D.C.

Li, S. (2015). Better lucky than rich? Welfare analysis of automobile license allocations in Beijing and Shanghai. Working paper, Cornell University.

Mian, A. and A. Sufi (2012). The effects of fiscal stimulus: Evidence from the 2009 cash for clunkers program. The Quarterly Journal of Economics 127(3), 1107-1142.

Ministry of Environmental Protection (2010). China vehicle emission control annual report 2010. Technical report, Beijing, China. 
Parry, I., D. Heine, E. Lis, and S. Li (2014). Getting Energy Prices Right: From Principle to Practice. International Monetary Fund, Washington, District of Columbia, U.S.A.

Sallee, J. M. and J. Slemrod (2012). Car notches: Strategic automaker responses to fuel economy policy. Journal of Public Economics 96, 981-999.

Viard, V. B. and S. Fu (2015). The effect of Beijing's driving restrictions on pollution and economic activity. Journal of Public Economics 125, 98-115.

Wang, Y., J. Hao, M. B. McElroy, J. W. Munger, H. Ma, D. Chen, and C. P. Nielsen (2009). Ozone air quality during the 2008 Beijing Olympics: Effectiveness of emission restrictions. Atmospheric Chemistry and Physics 9(14), 5237-5251.

World Health Organization (2013). Global status report on road safety 2013: Supporting a decade of action. Technical report, Geneva, Switzerland.

Xiao, J. and H. Ju (2014). Market equilibrium and the environmental effects of tax adjustments in China's automobile industry. Review of Economics and Statistics 96(2), $306-317$.

Xiao, J., X. Zhou, and W.-M. Hu (2015). Vehicle quota system and its impact on the Chinese auto markets. Working paper. 
Table 1: Eligibility and Vehicle Attributes

\begin{tabular}{|c|c|c|c|c|c|}
\hline & $\begin{array}{c}\text { Eligible } \\
\text { (1) }\end{array}$ & $\begin{array}{c}\text { Ineligible } \\
(2)\end{array}$ & $\begin{array}{c}\text { Difference } \\
(3)\end{array}$ & $\begin{array}{c}\text { Price R } \\
(4)\end{array}$ & $\begin{array}{c}\text { gression } \\
\quad(5)\end{array}$ \\
\hline Sales & $\begin{array}{c}57.248 \\
(86.814)\end{array}$ & $\begin{array}{c}30.091 \\
(42.037)\end{array}$ & $\begin{array}{c}27.157^{* *} \\
(6.941)\end{array}$ & & \\
\hline Price $(10,000 \mathrm{RMB})$ & $\begin{array}{c}9.181 \\
(4.171)\end{array}$ & $\begin{array}{l}7.688 \\
(2.452)\end{array}$ & $\begin{array}{l}1.494^{* *} \\
(0.374)\end{array}$ & & \\
\hline Automatic transmission & $\begin{array}{c}0.338 \\
(0.477)\end{array}$ & $\begin{array}{c}0.291 \\
(0.455)\end{array}$ & $\begin{array}{c}0.047 \\
(0.061)\end{array}$ & $\begin{array}{l}0.238^{+} \\
(0.133)\end{array}$ & $\begin{array}{c}0.043 \\
(0.128)\end{array}$ \\
\hline Engine size (liters) & $\begin{array}{c}1.431 \\
(0.157)\end{array}$ & $\begin{array}{c}1.463 \\
(0.179)\end{array}$ & $\begin{array}{l}-0.032 \\
(0.023)\end{array}$ & $\begin{array}{c}-3.049^{* *} \\
(1.023)\end{array}$ & $\begin{array}{c}-2.147^{+} \\
(1.136)\end{array}$ \\
\hline Fuel inefficiency (liters/100 km) & $\begin{array}{c}6.526 \\
(0.500)\end{array}$ & $\begin{array}{c}7.269 \\
(0.605)\end{array}$ & $\begin{array}{c}-0.743^{* *} \\
(0.078)\end{array}$ & $\begin{array}{c}-0.483^{*} \\
(0.214)\end{array}$ & $\begin{array}{l}-0.215 \\
(0.228)\end{array}$ \\
\hline Horsepower (kw) & $\begin{array}{c}80.103 \\
(15.041)\end{array}$ & $\begin{array}{c}72.754 \\
(11.294)\end{array}$ & $\begin{array}{l}7.350^{* *} \\
(1.595)\end{array}$ & $\begin{array}{l}0.074^{* *} \\
(0.016)\end{array}$ & $\begin{array}{l}0.049^{*} \\
(0.020)\end{array}$ \\
\hline Size $\left(m^{3}\right)$ & $\begin{array}{l}10.988 \\
(1.204)\end{array}$ & $\begin{array}{l}10.591 \\
(1.145)\end{array}$ & $\begin{array}{l}0.397^{*} \\
(0.154)\end{array}$ & $\begin{array}{c}0.046 \\
(0.131)\end{array}$ & $\begin{array}{l}-0.164 \\
(0.128)\end{array}$ \\
\hline Weight (kg) & $\begin{array}{l}1196.809 \\
(164.377)\end{array}$ & $\begin{array}{l}1141.433 \\
(123.147)\end{array}$ & $\begin{array}{l}55.376^{* *} \\
(17.403)\end{array}$ & $\begin{array}{l}0.013^{* *} \\
(0.002)\end{array}$ & $\begin{array}{l}0.015^{* *} \\
(0.002)\end{array}$ \\
\hline Chinese & $\begin{array}{c}0.324 \\
(0.471)\end{array}$ & $\begin{array}{c}0.504 \\
(0.501)\end{array}$ & $\begin{array}{c}-0.181^{* *} \\
(0.066)\end{array}$ & $\begin{array}{c}-2.236^{* *} \\
(0.193)\end{array}$ & \\
\hline European & $\begin{array}{c}0.191 \\
(0.396)\end{array}$ & $\begin{array}{c}0.163 \\
(0.370)\end{array}$ & $\begin{array}{c}0.028 \\
(0.050)\end{array}$ & $\begin{array}{l}1.106^{* *} \\
(0.234)\end{array}$ & \\
\hline Japanese & $\begin{array}{c}0.132 \\
(0.341)\end{array}$ & $\begin{array}{c}0.166 \\
(0.373)\end{array}$ & $\begin{array}{l}-0.034 \\
(0.049)\end{array}$ & $\begin{array}{c}0.765^{* *} \\
(0.251)\end{array}$ & \\
\hline Korean & $\begin{array}{c}0.162 \\
(0.371)\end{array}$ & $\begin{array}{c}0.065 \\
(0.247)\end{array}$ & $\begin{array}{l}0.096^{* *} \\
(0.036)\end{array}$ & $\begin{array}{c}-0.627^{* *} \\
(0.207)\end{array}$ & \\
\hline U.S. & $\begin{array}{c}0.191 \\
(0.396)\end{array}$ & $\begin{array}{c}0.101 \\
(0.302)\end{array}$ & $\begin{array}{l}0.090^{*} \\
(0.042)\end{array}$ & & \\
\hline Eligibility & & & & $\begin{array}{c}-0.587^{* *} \\
(0.215)\end{array}$ & $\begin{array}{c}0.084 \\
(0.217)\end{array}$ \\
\hline Constant & & & & $\begin{array}{c}-3.898^{* *} \\
(0.930)\end{array}$ & $\begin{array}{c}-4.727^{* *} \\
(1.360)\end{array}$ \\
\hline $\begin{array}{l}\text { Observations } \\
\text { Manufacturer fixed effects }\end{array}$ & 68 & 337 & 405 & $\begin{array}{l}405 \\
\text { No }\end{array}$ & $\begin{array}{l}405 \\
\text { Yes }\end{array}$ \\
\hline
\end{tabular}

Notes: This table reports average monthly sales in a province and vehicle attributes for eligible and ineligible models sold between January 2010 and May 2010 (before the first wave of subsidies). All vehicles have an engine size less than or equal to 1.6 liters. Columns (4) and (5) report results from price regressions with country fixed effects and manufacturer fixed effects, respectively. ${ }^{+} p<0.10,{ }^{*} p<0.05,{ }^{* *} p<0.01$. 
Table 2: Seven Waves of the Cash Subsidy Program

\begin{tabular}{|c|c|c|c|c|c|c|c|c|c|}
\hline \multirow{2}{*}{ Wave } & \multirow{2}{*}{ Release date } & \multirow{2}{*}{$\begin{array}{l}\text { Number of } \\
\text { new (total) } \\
\text { models } \\
\text { subsidized } \\
\end{array}$} & \multicolumn{5}{|c|}{ Country } & \multirow{2}{*}{$\begin{array}{l}\text { Number }(\%) \text { of } \\
\text { models identified } \\
\text { in the data }\end{array}$} & \multirow{2}{*}{$\begin{array}{l}\text { Number }(\%) \text { of } \\
\text { models launched } \\
\text { after receiving a } \\
\text { subsidy }\end{array}$} \\
\hline & & & cn & $\mathrm{eu}$ & jp & $\mathrm{kr}$ & us & & \\
\hline 1 & June 18, 2010 & $68(68)$ & 30 & 7 & 5 & 12 & 14 & $56(82.4 \%)$ & $20(35.7 \%)$ \\
\hline 2 & August 11, 2010 & $61(129)$ & 27 & 10 & 9 & 4 & 11 & $47(77.0 \%)$ & $21(44.7 \%)$ \\
\hline 3 & September 25, 2010 & $74(203)$ & 51 & 4 & 13 & 3 & 3 & $52(70.3 \%)$ & $43(82.7 \%)$ \\
\hline 4 & November 23, 2010 & $66(269)$ & 42 & 12 & 2 & 10 & 0 & $45(68.2 \%)$ & $35(77.8 \%)$ \\
\hline 5 & February 11, 2011 & $69(338)$ & 47 & 2 & 17 & 2 & 1 & $28(40.6 \%)$ & $10(35.7 \%)$ \\
\hline 6 & May 11, 2011 & $85(423)$ & 60 & 8 & 17 & 0 & 0 & $34(40.0 \%)$ & $21(61.8 \%)$ \\
\hline 7 & October 17, 2011 & $19(49)$ & 15 & 0 & 0 & 0 & 4 & $1(5.3 \%)$ & $0(0 \%)$ \\
\hline Total & & 442 & 272 & 43 & 63 & 31 & 33 & $263(59.5 \%)$ & $150(57.0 \%)$ \\
\hline
\end{tabular}

Notes: 'cn': indigenous brands, 'eu': European brands, ‘jp': Japanese brands, 'kr': Korean brands, 'us': U.S. brands.

Table 3: Summary Statistics

\begin{tabular}{lrrrrr}
\hline \hline & $\mathrm{N}$ & mean & s.d & min & $\max$ \\
\hline Panel A: Variables at the vehicle level & & & & & \\
Monthly sales in a province (Sales) & 703559 & 36 & 92.9 & 1 & 5066 \\
Eligibility & 703559 & 0.14 & 0.35 & 0 & 1 \\
Engine size (liters) & 703559 & 1.79 & 0.48 & 0 & 5.7 \\
Fuel inefficiency (liters/100 km) & 640781 & 7.98 & 1.4 & 2.7 & 14.7 \\
Gasoline expenditure (Gas, RMB/100 km) & 640781 & 49.6 & 9.8 & 16.2 & 104.2 \\
Horsepower (kw) & 559716 & 92.5 & 28 & 26.5 & 252 \\
Weight (kg) & 640781 & 1344.7 & 273.6 & 645 & 2690 \\
& & & & & \\
Panel B: Variables at the province level & & & & & \\
High school degree (\%) & 31 & 25.25 & 8.49 & 10.95 & 54.96 \\
Rural population (\%) & 31 & 48.57 & 14.56 & 10.69 & 76.31 \\
Average wage (RMB) & 31 & 36,103 & 9,652 & 27,735 & 66,115 \\
Share of fuel inefficient models before the 1st wave (\%) & 31 & 39 & 3.2 & 35.2 & 47.8 \\
\hline \hline
\end{tabular}

Notes: Demographic variables at the province level are obtained from China Statistical Yearbook 2011. 'Share of fuel inefficient models before the 1st wave' is the average share of vehicles sold within a province before the 1st wave that have fuel inefficiency/curb weight combinations above the bivariate regression fitted line. 
Table 4: Effect of the Subsidy on Vehicle Sales

\begin{tabular}{lccc}
\hline \hline & $(1)$ & $(2)$ & $(3)$ \\
\hline Receiving a subsidy & $0.668^{* *}$ & $0.652^{* *}$ & $0.684^{* *}$ \\
& $(0.152)$ & $(0.152)$ & $(0.152)$ \\
Gasoline expenditure & $0.090^{* *}$ & $0.100^{* *}$ & 0.002 \\
& $(0.016)$ & $(0.019)$ & $(0.024)$ \\
Observations & 429381 & 384438 & 384438 \\
\hline Birth quarter $\times$ age controls & No & Yes & Yes \\
Category $\times$ trend controls & No & No & Yes \\
Drop Beijing and Shanghai? & Yes & Yes & Yes \\
\hline \hline
\end{tabular}

Notes: This table reports estimates of equation (1) using variation from the first six waves. The dependent variable is the natural log of monthly vehicle model sales in a province. Months in which a new wave of subsidy began to take place were excluded. All regressions include vehicle model, province, and month-ofsample fixed effects. Standard errors are clustered at the vehicle model level. ${ }^{* *} p<0.01$. 
Table 5: Substitution Effect of the Subsidy

\begin{tabular}{|c|c|c|c|c|c|c|}
\hline & $\begin{array}{c}(1) \\
\text { Fuel } \\
\text { Inefficiency }\end{array}$ & $\begin{array}{c}(2) \\
\text { Engine } \\
\text { Size } \\
\end{array}$ & $\begin{array}{c}(3) \\
\text { Weight }\end{array}$ & $\begin{array}{c}(4) \\
\text { Fuel } \\
\text { Inefficiency }\end{array}$ & $\begin{array}{c}(5) \\
\text { Engine } \\
\text { Size }\end{array}$ & $\begin{array}{c}(6) \\
\text { Weight }\end{array}$ \\
\hline Receiving a subsidy & $\begin{array}{l}0.659^{* *} \\
(0.175)\end{array}$ & $\begin{array}{l}0.415^{*} \\
(0.173)\end{array}$ & $\begin{array}{c}0.540^{* *} \\
(0.180)\end{array}$ & $\begin{array}{c}0.625^{* *} \\
(0.183)\end{array}$ & $\begin{array}{l}0.323^{+} \\
(0.181)\end{array}$ & $\begin{array}{l}0.454^{*} \\
(0.190)\end{array}$ \\
\hline Unlisted $\times$ Post $\times$ Attribute quartile 1 & $\begin{array}{l}-0.292^{*} \\
(0.136)\end{array}$ & $\begin{array}{c}-0.513^{* *} \\
(0.139)\end{array}$ & $\begin{array}{l}-0.294^{*} \\
(0.130)\end{array}$ & $\begin{array}{l}-0.324^{*} \\
(0.145)\end{array}$ & $\begin{array}{c}-0.601^{* *} \\
(0.150)\end{array}$ & $\begin{array}{c}-0.377^{* *} \\
(0.145)\end{array}$ \\
\hline Unlisted $\times$ Post $\times$ Attribute quartile 2 & $\begin{array}{c}0.001 \\
(0.108)\end{array}$ & $\begin{array}{c}-0.445^{* *} \\
(0.098)\end{array}$ & $\begin{array}{c}-0.320^{* *} \\
(0.119)\end{array}$ & $\begin{array}{l}-0.029 \\
(0.121)\end{array}$ & $\begin{array}{c}-0.531^{* *} \\
(0.111)\end{array}$ & $\begin{array}{c}-0.401^{* *} \\
(0.135)\end{array}$ \\
\hline Unlisted $\times$ Post $\times$ Attribute quartile 3 & $\begin{array}{l}-0.009 \\
(0.105)\end{array}$ & $\begin{array}{l}-0.080 \\
(0.125)\end{array}$ & $\begin{array}{c}0.017 \\
(0.105)\end{array}$ & $\begin{array}{l}-0.035 \\
(0.114)\end{array}$ & $\begin{array}{l}-0.153 \\
(0.128)\end{array}$ & $\begin{array}{l}-0.050 \\
(0.113)\end{array}$ \\
\hline Post $\times$ Listed but not subsidized yet & $\begin{array}{c}0.169 \\
(0.138)\end{array}$ & $\begin{array}{l}-0.053 \\
(0.134)\end{array}$ & $\begin{array}{c}0.063 \\
(0.141)\end{array}$ & $\begin{array}{c}0.137 \\
(0.147)\end{array}$ & $\begin{array}{l}-0.143 \\
(0.143)\end{array}$ & $\begin{array}{l}-0.022 \\
(0.153)\end{array}$ \\
\hline Pre-event window $\times$ Close substitutes & & & & $\begin{array}{l}-0.067 \\
(0.059)\end{array}$ & $\begin{array}{c}-0.179^{* *} \\
(0.054)\end{array}$ & $\begin{array}{c}-0.177^{* *} \\
(0.061)\end{array}$ \\
\hline Gasoline expenditure & $\begin{array}{l}-0.008 \\
(0.021)\end{array}$ & $\begin{array}{l}-0.007 \\
(0.023)\end{array}$ & $\begin{array}{l}-0.004 \\
(0.023)\end{array}$ & $\begin{array}{l}-0.011 \\
(0.021)\end{array}$ & $\begin{array}{l}-0.010 \\
(0.023)\end{array}$ & $\begin{array}{l}-0.007 \\
(0.023)\end{array}$ \\
\hline Observations & 384438 & 384438 & 384438 & 384438 & 384438 & 384438 \\
\hline Birth quarter $\times$ age controls & Yes & Yes & Yes & Yes & Yes & Yes \\
\hline Category $\times$ trend controls & Yes & Yes & Yes & Yes & Yes & Yes \\
\hline Drop Beijing and Shanghai? & Yes & Yes & Yes & Yes & Yes & Yes \\
\hline
\end{tabular}

Notes: This table reports estimates of equation (2) using variation from the first six waves, with different comparison groups (the fourth attribute quartile) constructed based on vehicle attributes given in column headings. The dependent variable is the natural log of monthly vehicle model sales in a province. Months in which a new wave of subsidy began to take place were excluded. The average fuel inefficiencies of unsubsidized vehicle models in the first three quartiles are 6.62, 7.48, and 8.38 liters $/ 100 \mathrm{~km}$, respectively. The average engine sizes of unsubsidized vehicle models in the first three quartile are 1.25, 1.57, and 1.8 liters, respectively. The average weights of unsubsidized vehicle models in the first three quartiles are 1048, 1222, and $1429 \mathrm{~kg}$, respectively. All regressions include vehicle model, province, and month-of-sample fixed effects. Standard errors are clustered at the vehicle model level. ${ }^{+} p<0.10,{ }^{*} p<0.05,{ }^{* *} p<0.01$. 
Table 6: Share of Fuel Inefficient Models and Program Participation

\begin{tabular}{|c|c|c|c|}
\hline & $(1)$ & $(2)$ & $(3)$ \\
\hline \multirow[t]{2}{*}{ Receiving a subsidy } & $1.640^{* *}$ & $1.553^{* *}$ & $0.916^{* *}$ \\
\hline & $(0.295)$ & $(0.302)$ & $(0.342)$ \\
\hline \multirow[t]{2}{*}{ Unlisted $\times$ Post $\times$ Attribute quartile 1} & $-0.323^{*}$ & $-1.077^{* *}$ & $-1.076^{* *}$ \\
\hline & $(0.145)$ & $(0.313)$ & $(0.313)$ \\
\hline \multirow[t]{2}{*}{ Unlisted $\times$ Post $\times$ Attribute quartile 2} & -0.029 & -0.317 & -0.316 \\
\hline & $(0.121)$ & $(0.270)$ & $(0.270)$ \\
\hline \multirow[t]{2}{*}{ Unlisted $\times$ Post $\times$ Attribute quartile 3} & -0.035 & -0.023 & -0.023 \\
\hline & $(0.114)$ & $(0.251)$ & $(0.251)$ \\
\hline \multirow[t]{2}{*}{ Post $\times$ Listed but not subsidized } & 0.138 & 0.138 & 0.139 \\
\hline & $(0.147)$ & $(0.147)$ & $(0.147)$ \\
\hline \multirow[t]{2}{*}{ Pre-event window $\times$ Close substitutes } & -0.067 & -0.067 & -0.067 \\
\hline & $(0.059)$ & $(0.059)$ & $(0.059)$ \\
\hline \multirow[t]{2}{*}{ Gasoline expenditure } & -0.011 & -0.011 & -0.011 \\
\hline & $(0.021)$ & $(0.021)$ & $(0.021)$ \\
\hline \multirow[t]{2}{*}{ Receiving a subsidy $\times$ Share of fuel inefficient models } & $-0.026^{* *}$ & $-0.024^{* *}$ & $-0.028^{* *}$ \\
\hline & $(0.005)$ & $(0.006)$ & $(0.006)$ \\
\hline \multirow[t]{2}{*}{ Unlisted $\times$ Post $\times$ Attribute quartile $1 \times$ Share of fuel inefficient models } & & $0.019^{* *}$ & $0.019^{* *}$ \\
\hline & & $(0.007)$ & $(0.007)$ \\
\hline \multirow[t]{2}{*}{ Unlisted $\times$ Post $\times$ Attribute quartile $2 \times$ Share of fuel inefficient models } & & 0.007 & 0.007 \\
\hline & & $(0.006)$ & $(0.006)$ \\
\hline \multirow[t]{2}{*}{ Unlisted $\times$ Post $\times$ Attribute quartile $3 \times$ Share of fuel inefficient models } & & -0.000 & -0.000 \\
\hline & & $(0.005)$ & $(0.005)$ \\
\hline \multirow[t]{2}{*}{ Receiving a subsidy $\times$ High school degree } & & & $0.021^{* *}$ \\
\hline & & & $(0.004)$ \\
\hline \multirow[t]{2}{*}{ Receiving a subsidy $\times$ Rural population } & & & $0.007^{* *}$ \\
\hline & & & $(0.002)$ \\
\hline \multirow[t]{2}{*}{ Receiving a subsidy $\times$ Average wage } & & & -0.001 \\
\hline & & & $(0.004)$ \\
\hline Observations & 384438 & 384438 & 384438 \\
\hline Birth quarter $\times$ age controls & Yes & Yes & Yes \\
\hline Category $\times$ trend controls & Yes & Yes & Yes \\
\hline Drop Beijing and Shanghai? & Yes & Yes & Yes \\
\hline
\end{tabular}

Notes: The dependent variable is the natural log of monthly vehicle model sales in a province. Vehicles in the fourth quartile of fuel inefficiency are used to construct the comparison group. Months in which a new wave of subsidy began to take place were excluded. All regressions include vehicle model, province, and month-of-sample fixed effects. Standard errors are clustered at the vehicle model level. ${ }^{*} p<0.05,{ }^{* *} p<0.01$. 
Table 7: Including Samples from Beijing and Shanghai or from the Seventh Wave

\begin{tabular}{|c|c|c|c|c|c|c|}
\hline & (1) & $(2)$ & $(3)$ & (4) & $(5)$ & $(6)$ \\
\hline & Fuel & Engine & Weight & Fuel & Engine & Weight \\
\hline & Inefficiency & Size & & Inefficiency & Size & \\
\hline \multirow[t]{2}{*}{ Receiving a subsidy } & $0.617^{* *}$ & $0.310^{+}$ & $0.447^{*}$ & $0.655^{* *}$ & $0.321^{+}$ & $0.458^{*}$ \\
\hline & $(0.173)$ & $(0.171)$ & $(0.180)$ & $(0.194)$ & $(0.192)$ & $(0.202)$ \\
\hline \multirow[t]{2}{*}{ Unlisted $\times$ Post $\times$ Attribute quartile 1} & $-0.309^{*}$ & $-0.580^{* *}$ & $-0.357^{*}$ & $-0.337^{*}$ & $-0.616^{* *}$ & $-0.388^{*}$ \\
\hline & $(0.141)$ & $(0.145)$ & $(0.141)$ & $(0.154)$ & $(0.157)$ & $(0.152)$ \\
\hline \multirow[t]{2}{*}{ Unlisted $\times$ Post $\times$ Attribute quartile 2} & -0.007 & $-0.512^{* *}$ & $-0.375^{* *}$ & 0.009 & $-0.546^{* *}$ & $-0.408^{* *}$ \\
\hline & $(0.116)$ & $(0.108)$ & $(0.130)$ & $(0.127)$ & $(0.116)$ & $(0.143)$ \\
\hline \multirow[t]{2}{*}{ Unlisted $\times$ Post $\times$ Attribute quartile 3} & -0.020 & -0.161 & -0.043 & -0.005 & -0.166 & -0.052 \\
\hline & $(0.110)$ & $(0.122)$ & $(0.109)$ & $(0.122)$ & $(0.132)$ & $(0.120)$ \\
\hline \multirow[t]{2}{*}{ Post $\times$ Listed but not subsidized yet } & 0.142 & -0.142 & -0.016 & 0.128 & -0.181 & -0.056 \\
\hline & $(0.142)$ & $(0.138)$ & $(0.148)$ & $(0.159)$ & $(0.154)$ & $(0.165)$ \\
\hline \multirow[t]{2}{*}{ Pre-event window $\times$ Close substitutes } & -0.053 & $-0.173^{* *}$ & $-0.164^{* *}$ & -0.041 & $-0.165^{* *}$ & $-0.165^{*}$ \\
\hline & $(0.058)$ & $(0.053)$ & $(0.060)$ & $(0.061)$ & $(0.055)$ & $(0.064)$ \\
\hline \multirow[t]{2}{*}{ Gasoline expenditure } & -0.010 & -0.011 & -0.008 & -0.006 & -0.010 & -0.006 \\
\hline & $(0.021)$ & $(0.022)$ & $(0.022)$ & $(0.021)$ & $(0.024)$ & $(0.023)$ \\
\hline \multirow[t]{2}{*}{ Stopping a subsidy } & & & & $0.765^{* *}$ & $0.415^{*}$ & $0.561^{*}$ \\
\hline & & & & $(0.212)$ & $(0.210)$ & $(0.221)$ \\
\hline Observations & 408762 & 408762 & 408762 & 443916 & 443916 & 443916 \\
\hline Birth quarter $\times$ age controls & Yes & Yes & Yes & Yes & Yes & Yes \\
\hline Category $\times$ trend controls & Yes & Yes & Yes & Yes & Yes & Yes \\
\hline Include Beijing and Shanghai? & Yes & Yes & Yes & No & No & No \\
\hline Include the seventh wave? & No & No & No & Yes & Yes & Yes \\
\hline
\end{tabular}

Notes: This table reports estimates of equation (2), with different comparison groups constructed based on vehicle attributes given in column headings. The dependent variable is the natural log of monthly vehicle model sales in a province. Months in which a new wave of subsidy began to take place were excluded. Columns (1)-(3) report estimated coefficients using the variation from the first six waves including Beijing and Shanghai, while columns (4)-(6) report estimated coefficients from the first seventh waves (excluding Beijing and Shanghai). All regressions include vehicle model, province, and month-of-sample fixed effects. Standard errors are clustered at the vehicle model level. ${ }^{+} p<0.10,{ }^{*} p<0.05,{ }^{* *} p<0.01$. 
Table 8: Including the First Months Being Subsidized

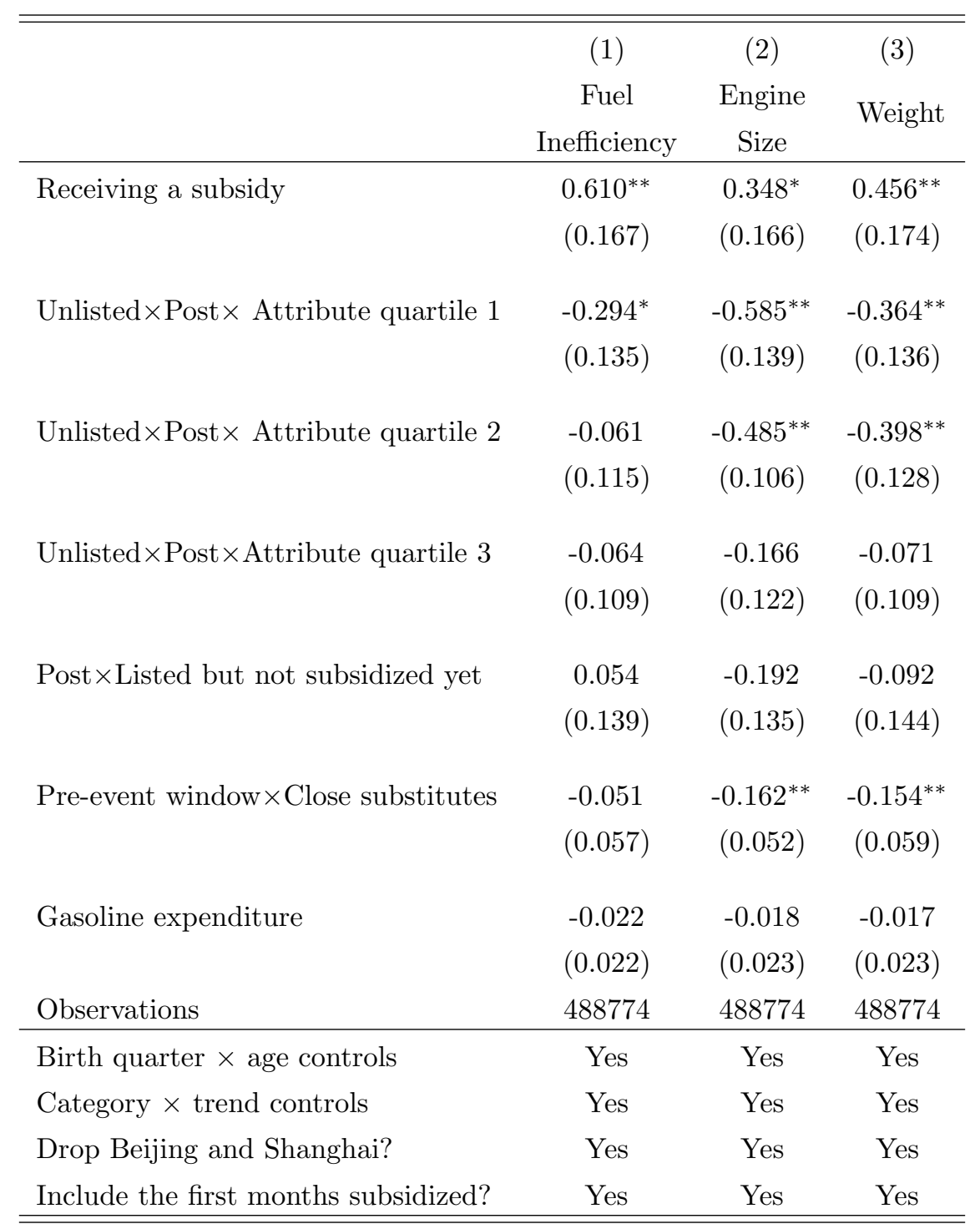

Notes: This table reports estimates of equation (2) using variation from the first six waves, with different comparison groups constructed based on vehicle attributes given in column headings. The dependent variable is the natural $\log$ of monthly vehicle model sales in a province. Months in which a new wave of subsidy began to take place were included. We adjust the variables "Receiving a subsidy", "Post", and "Pre-event window" to reflect the number of days a vehicle was being subsidized in a given month. All regressions include vehicle model, province, and month-of-sample fixed effects. Standard errors are clustered at the vehicle model level. ${ }^{*} p<0.05$, ${ }^{* *} p<0.01$. 
Table 9: Monthly Observed and Counterfactual Sales

\begin{tabular}{lccccc}
\hline \hline & $(1)$ & $(2)$ & $(3)$ & $(4)$ & $(5)$ \\
& $\begin{array}{c}\text { Avg. Fuel } \\
\text { Inefficiency }\end{array}$ & $\begin{array}{c}\text { Observed } \\
\text { Sales } \\
\text { (Before) }\end{array}$ & $\begin{array}{c}\text { Observed } \\
\text { Sales } \\
\text { (After) }\end{array}$ & $\begin{array}{c}\text { Counterfactual } \\
\text { Sales } \\
\text { (After) }\end{array}$ & $\begin{array}{c}\text { Difference } \\
(3)-(4)\end{array}$ \\
\hline Subsidized & 6.472 & 59,716 & 161,296 & 92,646 & 68,650 \\
Not subsidized (fuel ineff. quartile=1) & 6.704 & 79,985 & 59,888 & 82,763 & $-22,876$ \\
Not subsidized (fuel ineff. quartile=2) & 7.515 & 115,695 & 116,367 & 116,367 & 0 \\
Not subsidized (fuel ineff. quartile=3) & 8.435 & 109,366 & 100,718 & 100,718 & 0 \\
Not subsidized (fuel ineff. quartile=4) & 9.711 & 56,402 & 70,347 & 70,347 & 0 \\
New products (not subsidized) & 8.098 & - & 65,773 & 70,661 & $-4,888$ \\
New products (subsidized) & 6.553 & - & 98,653 & 52,797 & 45,856 \\
\hline Total sales & & 421,163 & 673,041 & 586,299 & $86,742(58918)$ \\
Average fuel inefficiency & & 7.703 & 7.476 & 7.641 & $-0.165^{+}(0.095)$ \\
\hline
\end{tabular}

Notes: We calculate monthly national sales for vehicle groups given in the column and row headings. Column (1) reports the average fuel inefficiency across groups after the program started but before the 7th wave. Column (2) reports observed sales from January 2009 to May 2010. Column (3) reports observed sales from July 2010 to September 2011 (before the 7th wave). Months in which a new wave of subsidy began to take place were excluded. Column (4) reports counterfactual sales based on the estimated coefficients (those with at least $5 \%$ statistical significance) from the fourth column of Table 5. We bootstrap across vehicle models to obtain standard errors (given in parentheses) for the program's effect on monthly sales and average fuel inefficiency. ${ }^{+} p<0.10$.

Table 10: Implied Price for Gasoline and Carbon Dioxide Saved

\begin{tabular}{lcccc}
\hline \hline & $(1)$ & $(2)$ & $(3)$ & $(4)$ \\
\hline Implied price of gasoline (USD/liter) & 0.193 & 0.226 & -0.04 & -0.047 \\
Implied price of CO2 (USD/ton) & 82 & 96 & -17 & -20 \\
Discount rate & $0 \%$ & $3 \%$ & $0 \%$ & $3 \%$ \\
Take changes in sales into account? & No & No & Yes & Yes \\
\hline
\end{tabular}

Notes: We calculate total gasoline and carbon dioxide saved by the subsidy program from July 2010 to September 2011 and the total amount paid by the program during this time (excluding Beijing and Shanghai). Average gasoline savings per vehicle sold during this time and additional sales generated by the program are from Table 9. We use 600,000 kilometers to calculate a vehicle's lifetime mileage. 
Table 11: Welfare Analysis

\begin{tabular}{|c|c|c|c|c|c|c|c|}
\hline$(1)$ & $(2)$ & $(3)$ & $(4)$ & $(5)$ & $(6)$ & $(7)$ & $(8)$ \\
\hline \multirow{2}{*}{$\begin{array}{l}\text { Gasoline savings } \\
\text { from a marginal } \\
\text { consumer } \\
(\text { liters } / 100 \mathrm{~km})\end{array}$} & \multirow[b]{2}{*}{$\begin{array}{c}\text { Share of } \\
\text { marginal } \\
\text { consumers }\end{array}$} & \multicolumn{3}{|c|}{ Discount rate: $0 \%$} & \multicolumn{3}{|c|}{ Discount rate: $3 \%$} \\
\hline & & $\begin{array}{c}\text { Marginal } \\
\text { benefit per } \\
\text { inducement } \\
(\mathrm{RMB})\end{array}$ & $\begin{array}{l}\text { Break- } \\
\text { even } \\
\eta\end{array}$ & $\begin{array}{c}\text { Break-even } \\
\text { marginal tax } \\
\text { when } \eta=1.3 \\
\text { (USD/liter) }\end{array}$ & $\begin{array}{c}\text { Marginal } \\
\text { benefit per } \\
\text { inducement } \\
(\mathrm{RMB})\end{array}$ & $\begin{array}{l}\text { Break- } \\
\text { even } \\
\eta\end{array}$ & $\begin{array}{c}\text { Break-even } \\
\text { marginal tax } \\
\text { when } \eta=1.3 \\
\text { (USD/liter) }\end{array}$ \\
\hline 0.201 & 0.465 & 1,036 & 0.928 & 0.431 & 884 & 0.904 & 0.506 \\
\hline 1.586 & 0.465 & 8,163 & 2.032 & 0.055 & 6,963 & 1.846 & 0.064 \\
\hline
\end{tabular}

Notes: The amount of subsidy received by each eligible vehicle was 3000 RMB. Columns (3) and (6) adopt estimates from Parry et al. (2014), assuming that marginal benefits from the reduction of air pollution and carbon dioxide in China are 0.05 and $0.08 \mathrm{USD} /$ liter, respectively. Columns (4) and (7) report the implied efficiency cost parameter $(\eta)$ in which the social benefit and the social cost are equal. Columns (5) and (8) assume that the efficiency cost parameter is fixed at 1.3 and report the underlying marginal tax (USD/liter) in which the social benefit and the social cost are equal. 


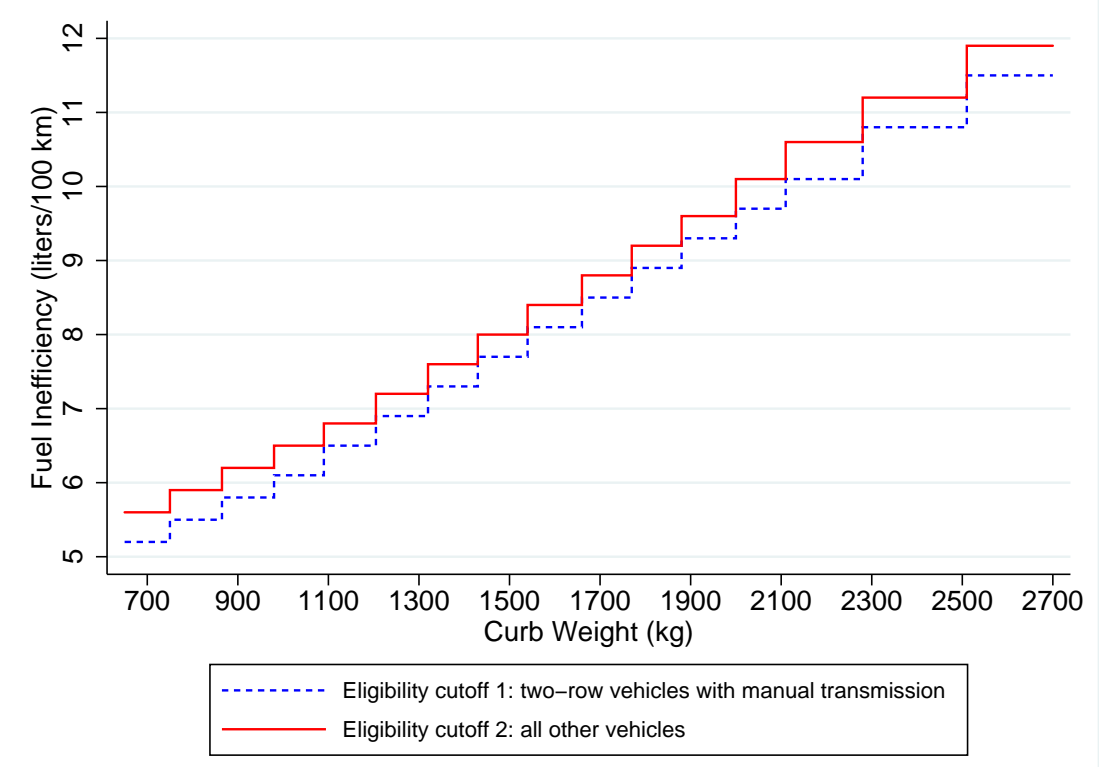

Figure 1: Subsidy Cutoffs for Different Types of Vehicles

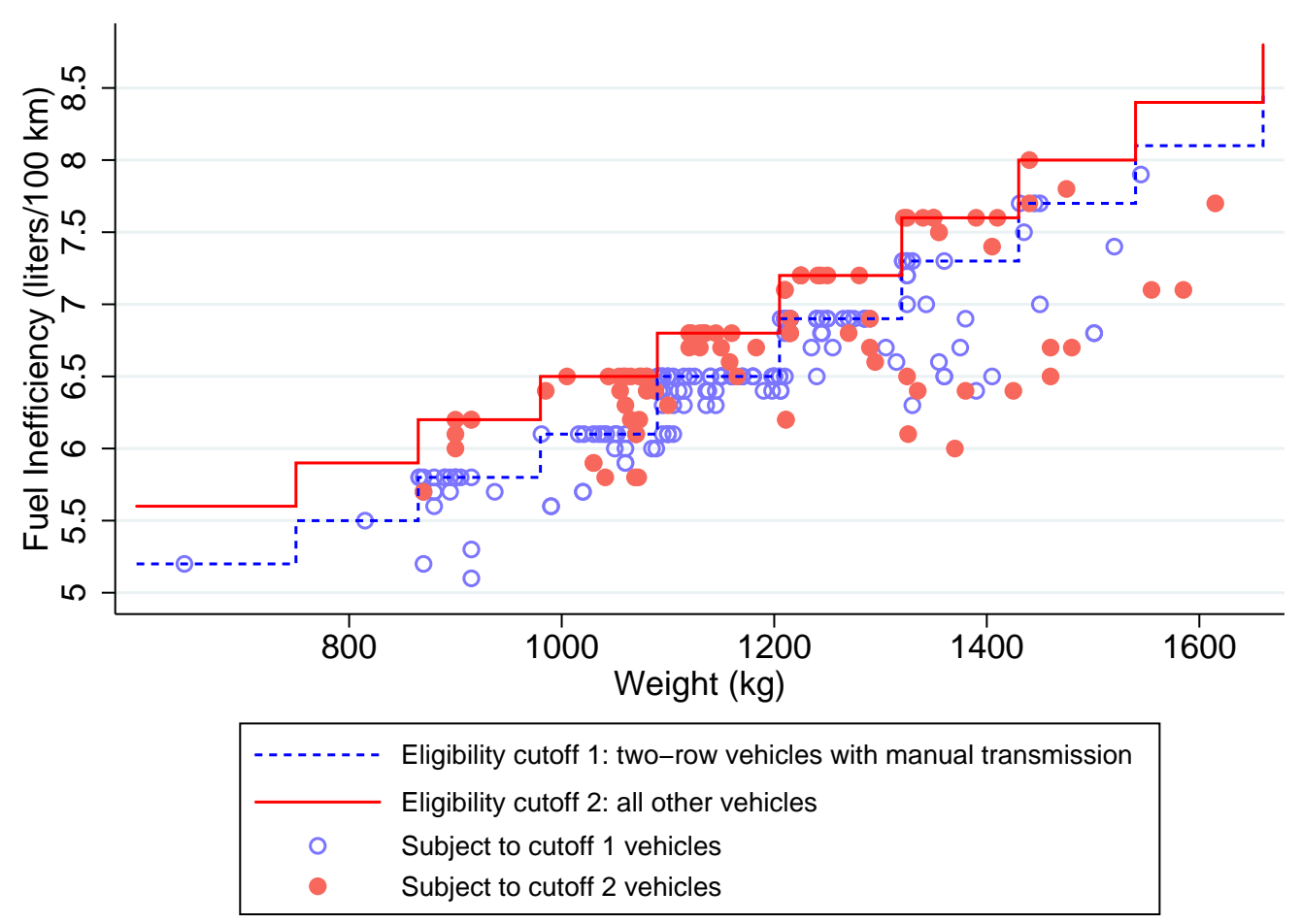

Figure 2: Fuel Inefficiency and Curb Weights: Subsidized Models 


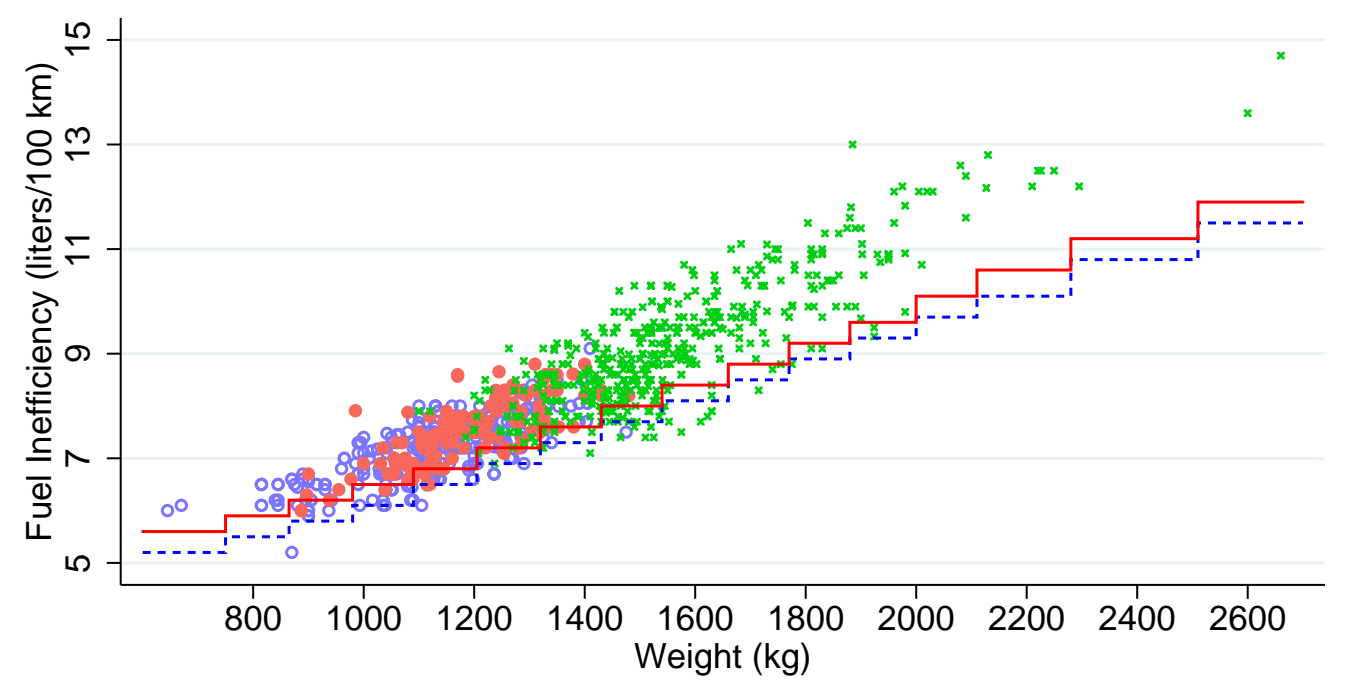

$\begin{array}{cl}- & \text { Eligibility cutoff } 1: \text { two-row vehicles with manual transmission } \\ & \text { Eligibility cutoff } 2: \text { all other vehicles } \\ & \text { Subject to cutoff } 1 \text { vehicles } \\ & \text { Subject to cutoff } 2 \text { vehicles } \\ & \text { Vehicles with an engine size greater than } 1.6 \text { liters }\end{array}$

Figure 3: Fuel Inefficiency and Curb Weights: Unsubsidized Models 


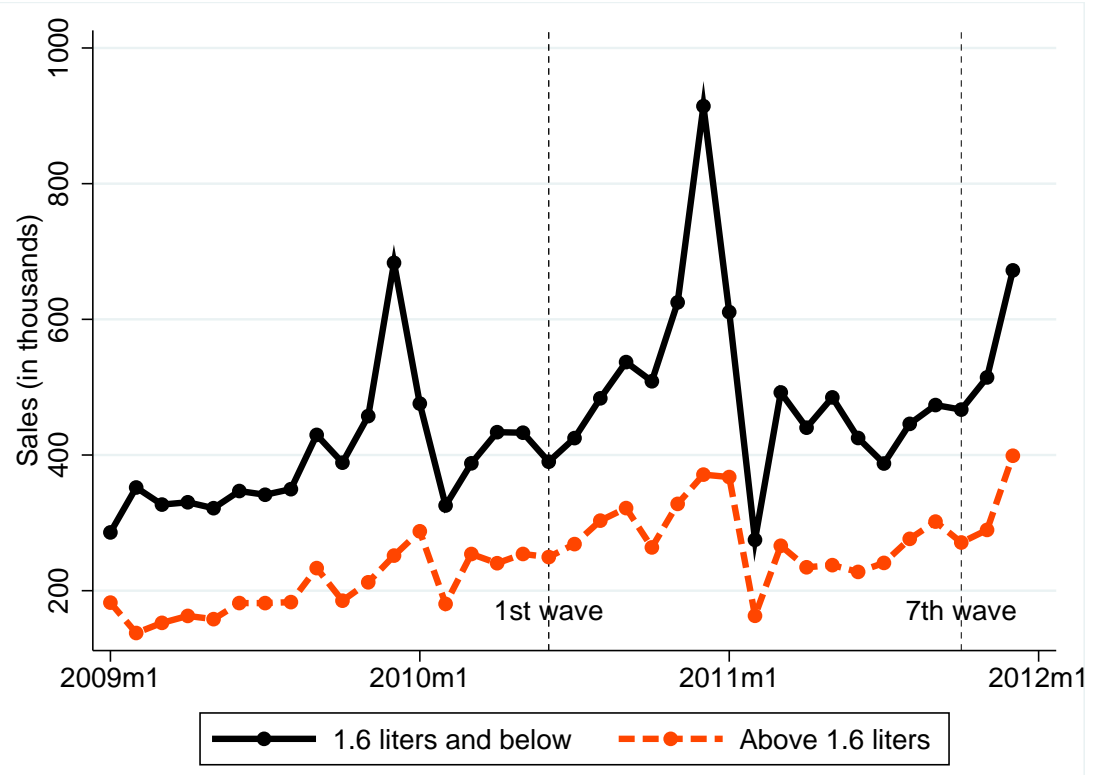

(a) All vehicles

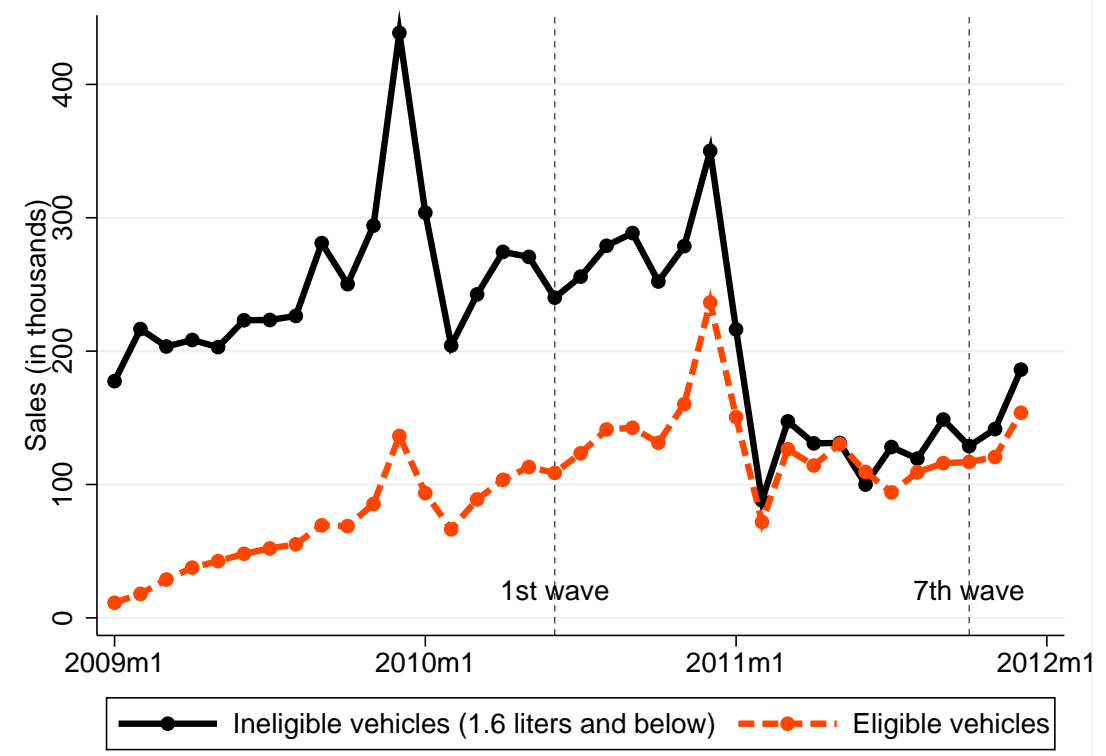

(b) Vehicles with sales before the program

Figure 4: Total Vehicle Sales 


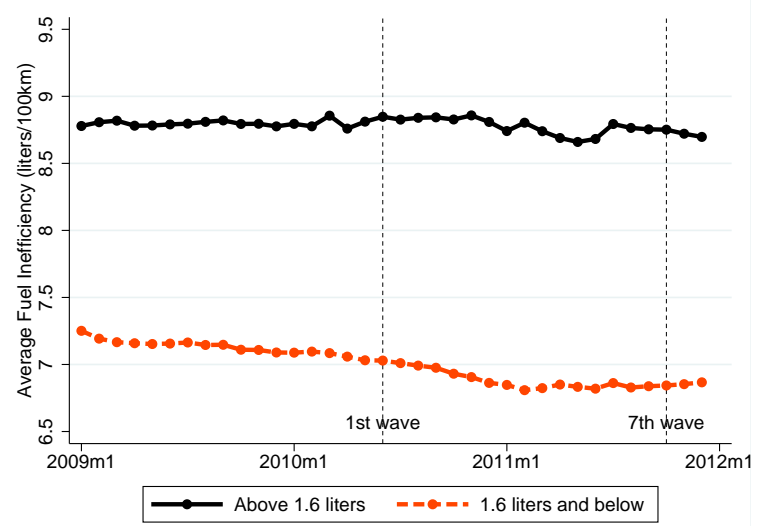

(a) Fuel inefficiency

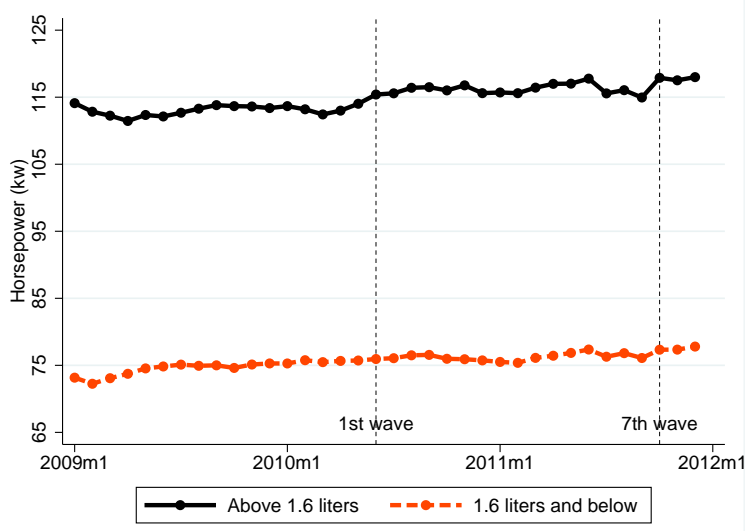

(c) Horsepower

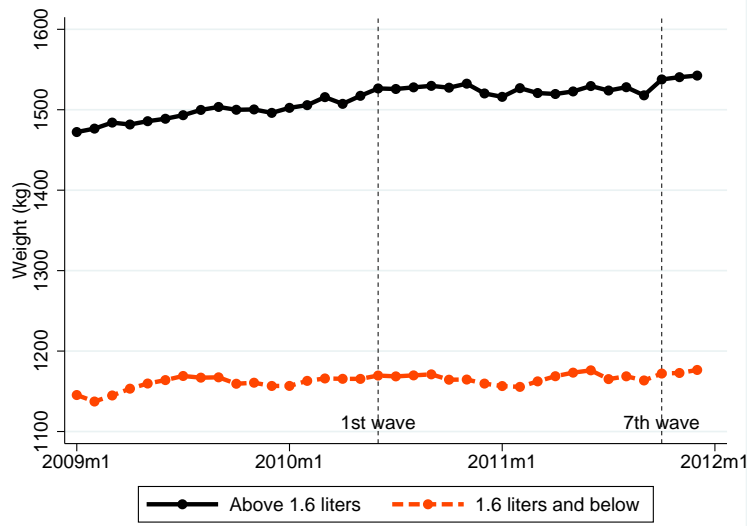

(b) Weight

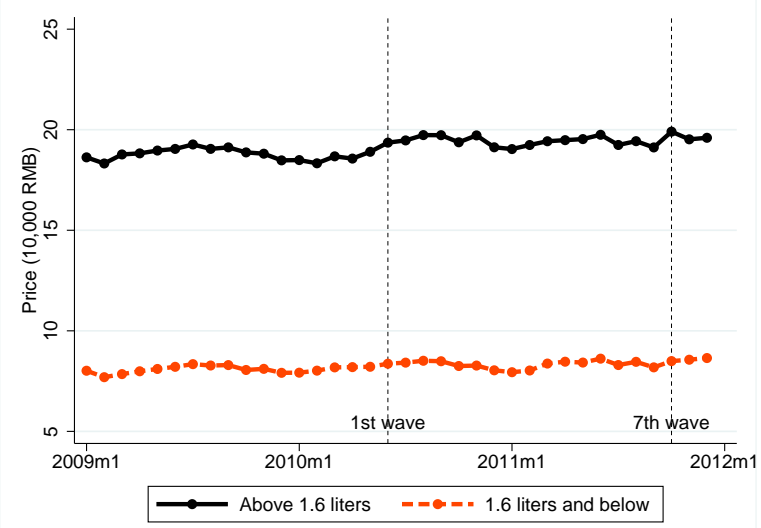

(d) Price

Figure 5: Vehicle Attributes

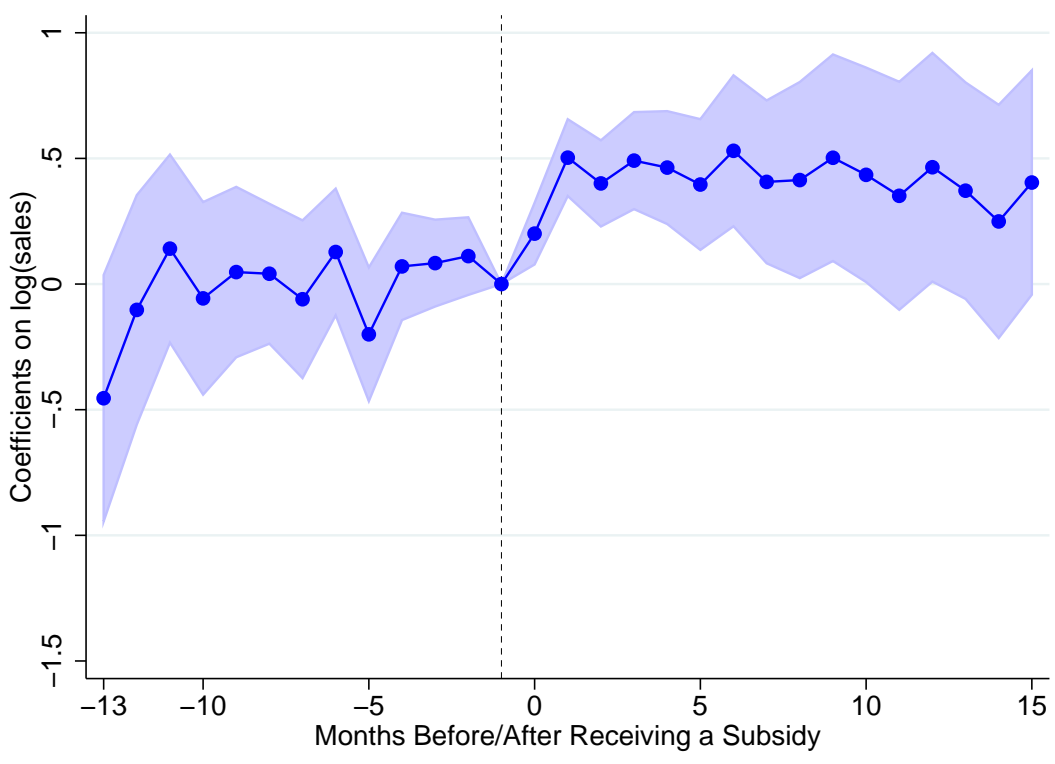

Figure 6: Intertemporal Substitution: Subsidized Products 


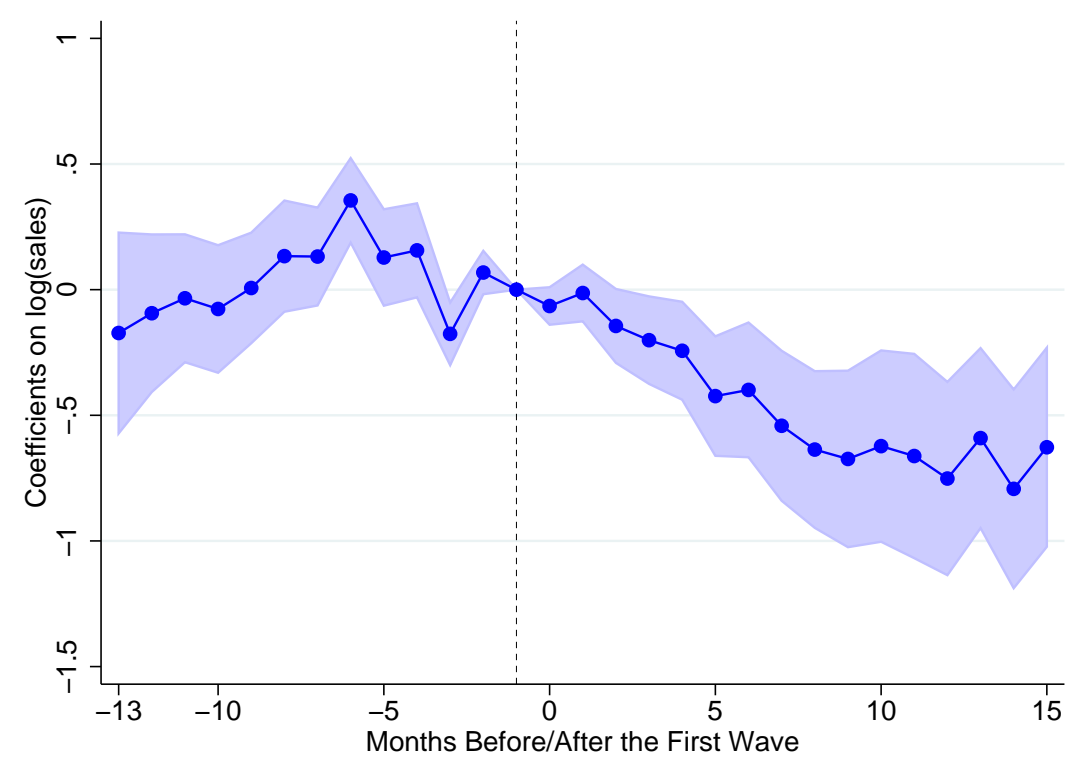

Figure 7: Intertemporal Substitution: Unsubsidized Products in Fuel Inefficiency Quartile 1

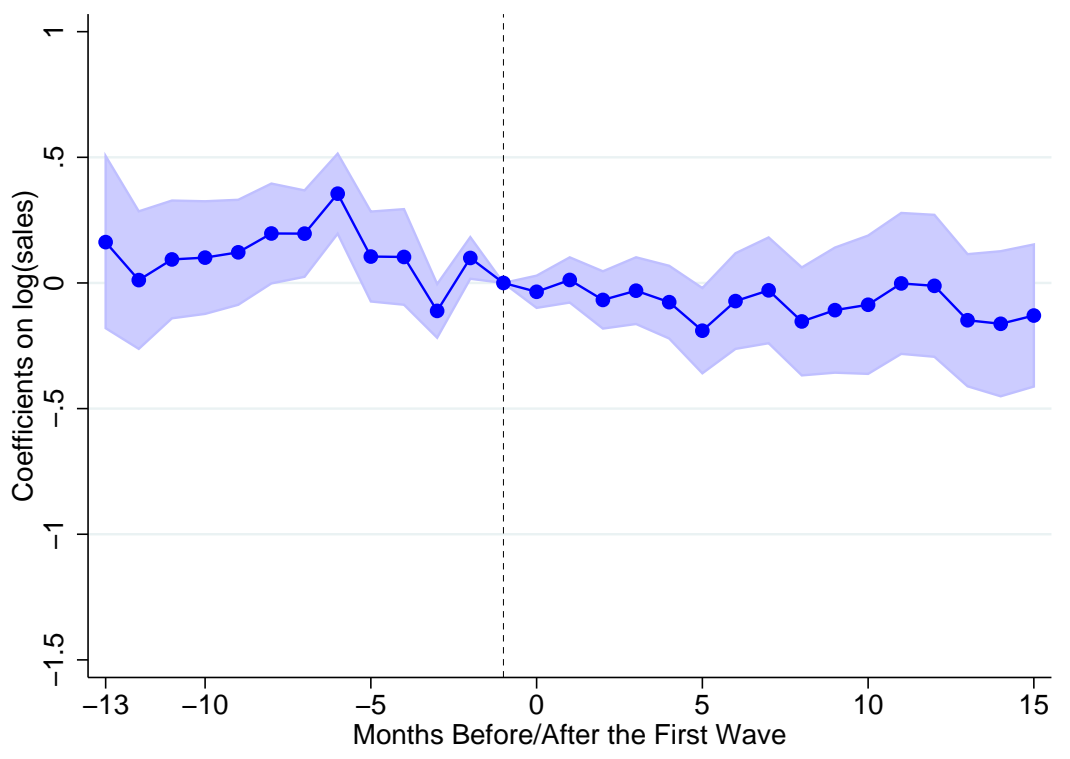

Figure 8: Intertemporal Substitution: Unsubsidized Products in Fuel Inefficiency Quartile 2 


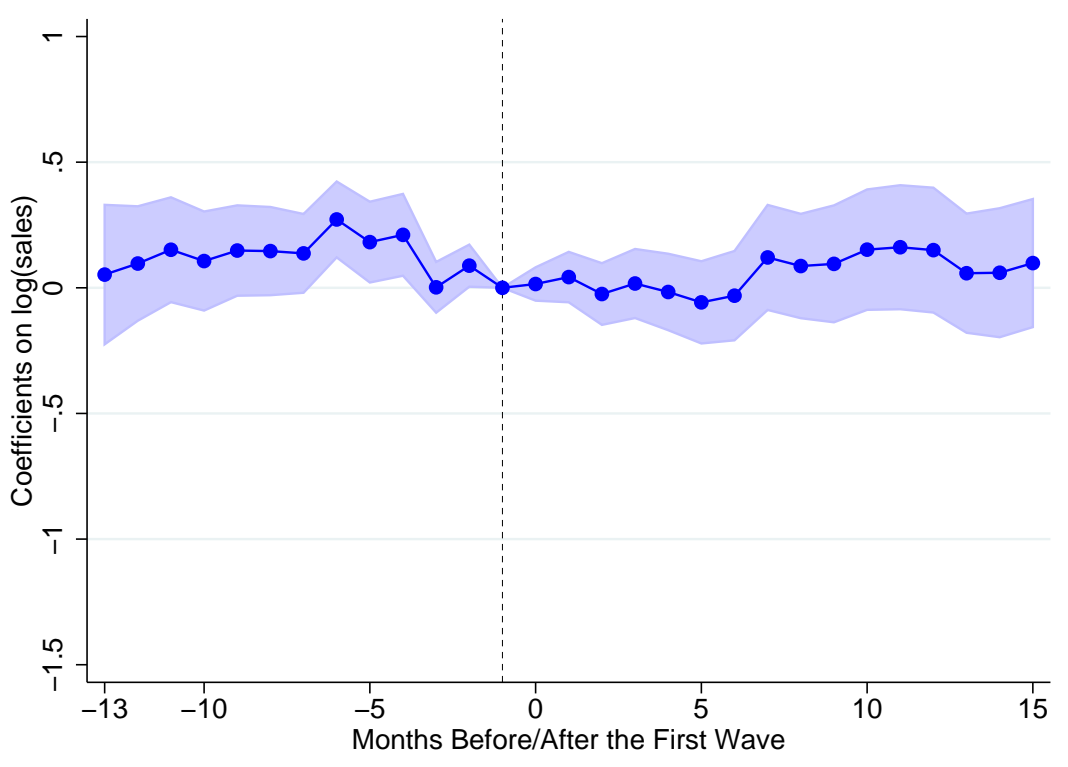

Figure 9: Intertemporal Substitution: Unsubsidized Products in Fuel Inefficiency Quartile 3 